Revista de Estudios Histórico-Jurídicos

[Sección Historia del Derecho Español]

XXXIV (Valparaíso, Chile, 2012)

[pp. 237 - 275]

\title{
Las treguas entre Granada y Castilla durante los SIGLOS XIII A XV
}

[The Truces Between Grenada and Castile During $13^{\text {nth }}$ and $15^{\text {nth }}$ Centuries]

\author{
Diego Melo Carrasco* \\ Universidad Adolfo Ibáñez, Santiago de Chile
}

\begin{abstract}
RESUMEN
Uno de los aspectos esenciales del espacio fronterizo entre Granada y Castilla durante los siglos XIII al XV fue definido por la dualidad de guerra y paz que allí se manifestó. El presente trabajo indaga en una de las instrucciones que mayor relevancia tendrá en el desarrollo de unas relaciones de corte pacífico en la frontera; nos referimos a las treguas.

En el presente artículo nos hemos centrado en los caracteres fundamentales de esta institución así como en su articulado, el cual es un fiel reflejo de las características de vida del territorio fronterizo, sus intercambios y enfrentamientos.

Palabras Clave

Frontera - Guerra - Paz - Treguas Articulado.
\end{abstract}

\begin{abstract}
One of the most important aspects regarding the borderline space between Grenada and Castile between the thirteenth and fifteenth centuries was defined by the war-peace dyad that took place in it. This work intends to investigate the most relevant aspects in the development of peace relationships at the frontier: the institution of the truce. The focus of this article is placed in the main characteristics if this institution and the way they articulate, as they represent a true reflection of the way of life in the borderline territory, the different interchanges that occurred in it, as well as its clashes.

\section{KeYwords} ticulate.
\end{abstract}

RECIBIDO el 11 de julio y ACEPTADO el 27 de julio de 2012

* Profesor adjunto de la Facultad de Artes Liberales de la Universidad Adolfo Ibáñez, Avda. Diagonal Las Torres 2640, Peñalolén, Santiago, Chile. diego.melo@uai.cl. Agradezco la ayuda y asistencia metodológica de la profesora Constanza López Lamerain. 


\section{ANTECEDENTES}

1. Uno de los aspectos esenciales del espacio fronterizo entre Granada y Castilla durante los siglos XIII al XV fue definido por la dualidad de guerra y paz que allí se manifestó ${ }^{1}$. Esa compleja realidad se hizo, a la vez, más específica ya que, tal como lo afirma Juan de Mata Carriazo: "en la frontera de Granada, la paz y la guerra no eran esas cosas rotundas de siempre y de todas partes, ni la paz era paz, ni la guerra era guerra, en el pleno sentido de cada concepto [...] ni aún las treguas eran tales treguas; todo lo más, un estado de guerra atenuado" ${ }^{2}$. En este sentido, lo más preciso es pensar en la existencia de tres estados: guerra, paz y, su intermedia, la tregua.

Desde ese punto de vista, es importante constatar que el estudio de las relaciones fronterizas se debe realizar desde la óptica de quienes las asentaron como razón y legitimación de poder socio-político. Dejando de lado los contactos bélicos, bien de tipo abierto (guerra declarada o batalla campal) o bien de carácter particular (la guerra "guerreada"), la cercanía y los inevitables roces cotidianos entre individuos de ambos lados, además de la actividad comercial, supusieron el nudo gordiano de las relaciones habituales entre cristianos y musulmanes ${ }^{3}$.

Este permanente trato ha generado un amplio debate entre de los historiadores que se han dedicado a la frontera de Granada, presentando dos visiones: por un lado queda la posición de unas relaciones francas y de cotidiano buen entendimiento, con la excepción marcada en los puntuales momentos de guerra abierta $y$, por otro, quienes interpretan esas relaciones como de obligada vecindad que busca la supervivencia, independiente de cómo se logre.

Es importante poner en claro esta visión ambivalente de la frontera y precisar, en especial, algunas consideraciones en torno a las relaciones fronterizas, ingresando en una institución tan peculiar como son las treguas ya que de ella derivan una serie de contactos y situaciones que permiten ampliar, algo más, el análisis sistemático de las mismas y la mirada en las relaciones que de cotidiano se manifestaron en ese espacio histórico.

2. Las treguas, en general, han sido de sobra estudiadas y muy bien tratadas en su día por los profesores Carriazo y Torres Fontes y, más recientemente, por el profesor López de Coca. Todos ellos coinciden en plantearnos ciertas características fundamentales para comprender dicha institución. En primer lugar, está perfectamente documentado que las treguas nunca tuvieron la condición de los tratados de paz definitivos y duraderos, como los que en algún momento se establecieron entre los reinos cristianos. Por su misma naturaleza, no reconocían

\footnotetext{
${ }^{1}$ TORREs FonTEs, Juan, Instituciones y sociedad en la frontera murciano-granadina (Murcia, Real Academia Alfonso X el Sabio, 2004), pp. 9-10.

${ }^{2}$ Carriazo y Arroquia, Juan de Mata, En la frontera de Granada (Granada, Universidad de Granada, 2002), pp. 215-216.

${ }^{3}$ Jiménez AlcÁZAR, Jesús Manuel, Relaciones interterritoriales en el sureste de la Península Ibérica durante la Baja Edad Media: Cartas, Mensajeros y Ciudades en la Frontera de Granada, en Anuario de Estudios Medievales, 40 (Barcelona, 2010) 2, pp. 565 ss., p. 583.
} 
más que una paz temporal. De no renovarse a su conclusión, ambas partes estaban legitimadas para reanudar hostilidades ${ }^{4}$.

En segundo lugar, hasta la llegada al poder de los Trastámara las treguas implicaban, por parte de Granada, el reconocimiento de la superioridad de Castilla, lo que se traducía en el pago de unos tributos anuales o "parias". Desde finales del siglo XIV, se ve cómo este proceder da paso a la práctica de la entrega de un determinado número de cautivos cristianos. Sin embargo, la cuestión semántica en el pago o entrega de cautivos es una situación que no deja de tener importancia, puesto que si para los cristianos podía considerarse como un signo de sometimiento o vasallaje, para los granadinos era simplemente una muestra de buena voluntad o una donación graciosa. En todo caso, los documentos reflejan esta situación ya que, la mayoría de veces, las treguas más importantes consideran el pago de tributo por parte de los granadinos ${ }^{5}$, el cual, en más de algún momento le significó un gran esfuerzo de pago ${ }^{6}$.

Por otra parte, en los lugares más alejados de la frontera, las treguas suponían un alivio económico, una vuelta a una cierta "normalidad" de la vida, que traía consigo la reanudación de los intercambios comerciales, la negociación y liberación de cautivos y la posibilidad de desarrollar actividades económicas sin el riesgo de ser sorprendido por el enemigo ${ }^{7}$. Es por esto que, una vez firmadas las treguas, el rey castellano o aragonés se preocupaba de comunicar el contenido de las mismas a los lugares fronterizos, a la vez que prohibía cualquier acto de fuerza contra los granadinos y autorizaba la reanudación del comercio. Quienes desarrollaban estas actividades portaban cartas de seguro ${ }^{8}$ entregadas por los

${ }^{4}$ GonZÁlez Jiménez, Manuel, La frontera entre Andalucía y Granada: realidades bélicas, en Ladero Quesada, Miguel Ángel (editor), La incorporación de Granada a la Corona de Castilla, Actas del Symposium conmemorativo del Quinto Centenario (Granada, Diputación Provincial de Granada, 1993), p. 97. "Guerra atenuada y vergonzante", en palabras de Carriazo, la tregua que en sentido estricto era interrupción, cese temporal de hostilidades, "sobreseimiento de guerra" como se expresa en las cartas reales. En TORRES FONTES, Juan, Dualidad Fronteriza: Guerra y paz, en Segura Artero, Pedro (coordinador), Actas del Congreso La Frontera Oriental Nazarí como Sujeto Histórico (S. XIII-XVI) (Almería, Instituto de Estudios Almerienses, 1997), p. 67.

${ }^{5}$ Según García Fernández, Manuel, Sobre la alteridad en la frontera de Granada (una aproximación al análisis de la guerra y la paz, siglos XIII-XV), en Revista da Faculta de de Letras. Historia, 6 (Porto, 2005), p. 229: “[...] (estas) fueron entendidas por los cristianos como un signo del sometimiento islámico materializado además en el pago de parias al reino de Castilla, 12.000 doblas de oro. Sin embargo, para el reino nazarí de Granada este símbolo tan sólo fue una muestra de buena voluntad y entendimiento pacífico, una manifestación de convivencia entre monarcas que se declaraban y sabían amigos y vasallos [...]",

${ }^{6} \mathrm{La}$ cuantía de las parias fue muy variable, y si, en un principio el pago de parias se había fijado en la mitad de las rentas del emir, luego la cantidad descendió mucho: en el siglo XV era corriente una cifra entre once mil y trece mil doblas de oro. Sobre el particular, véase: LADERO Quesada, Miguel Ángel, La frontera de Granada, 1265-1481, en Revista de Historia Militar, 1 (Madrid, 2002), pp. 49 ss. y 54.

${ }^{7}$ LADERO QUESADA, Miguel Ángel, La frontera, cit. (n. 6), pp. 102-103.

${ }^{8}$ Solo a modo de ejemplo reproducimos una de ellas: "Muy honrrado, esforçado, Fidalgo e presçiado, virtuoso e noble caballero el alcayde Abulcaçin Venegas, alguasil mayor del Señor Rey de Granada e del su Consejo: el conçejo etc. Nos vos encomendamos con voluntad muy presta de facer las cosas que ordenáres e mandares: Lorenço de Sella, genoués, morador de esta çibdad, va con nuestro 
concejos fronterizos. En ellas, estos se comprometían, formalmente, a cumplir y hacer cumplir la tregua?.

El comunicado oficial de la tregua, la mayoría de las veces de concesión castellana, también se hacía por parte granadina, si bien en forma ambigua, ya que era el modo de evadir o paliar su subordinación y dependencia. Como comunicación oficial, la tregua tenía carácter obligatorio, pero en el siglo XV se hizo frecuente el que, como carta real, se acatara y obedeciera, pero no siempre se cumpliera, pues muchas veces dependía de la situación de cada comarca o sector ${ }^{10}$.

El quebrantamiento de treguas era duramente castigado. Así se observa desde muy temprano en los textos jurídicos. En el Fuero de Andújar, de la familia de Cuenca, dado por Fernando III a la ciudad, se dice: "[M] ando que todo aquel que treguas de rrey o conçejo quebrantare, sea justiçiado sy prenderle pudieran. Sy por aventura escapare, pierda quanto oviere mueble e rraíz e métanlo en adobo de los muros de la villa" ${ }^{11}$. El pueblo estaba especialmente sensibilizado con la rigurosa exigencia. No faltan indicios de poblaciones que, por defender la situación de calma que proporcionan las paces y treguas, imponen ejemplares castigos a individuos de sus comunidades o regiones que las transgreden. Esta es la declaración de un testigo de un pleito sucedido por la zona de Zahara: "[...] antes quel duque [don Rodrigo Ponce de León] quemase Villaluenga Avía pazes entre Zahara y Ronda, $y$ los de Syerra de Villaluenga no las guardavan, y los de Ronda ahorcaron cerca de Zahara un moro de la Syerra, porque venía a hurtar a los de Zahara y no guardavan las pazes"12.

En general, los documentos dan cuenta de las treguas y lo hacen con mayor

seguro a esa çibdad del Reyno de Granada negociar e librar çciertas cosas de sus mercaderías. Por ende, mucho... vos pedimos, asy porquel va con nuestro seguro como por nuestra contemplación, sea bien tratado e honrrado en esa çibdad e Reyno, en todas las cosas que ouiere menester, e no le sea fecho enojo ni daño alguno. E en esto, allende de... nuestro rruego nos rremaneçerremos en obligación para en las cosas que mandáredes las facer como propias nuestras. Nuestro Señor conserve vuestra virtuosa persona como... deseáis. De Jahén, XXXVI de nouiembre de LXXXIX años", Viernes 26-XI-1479, A.M.J., "Libro de Actas Capitulares", Doc. 171, en Carriazo y Arroquia, Juan de Mata, En la frontera, cit. (n. 2), p. 303.

${ }^{9}$ Carriazo y Arroquia, Juan de Mata, En la frontera, cit. (n. 2), p. 303.

${ }^{10}$ Torres Fontes, Juan, Dualidad, cit. (n. 4), p. 68. "Las muestras murcianas son abundantes en este aspecto. Lo fue con don Juan Manuel, eterno rebelde a Alfonso XI. En Murcia se supo con indignación que Pedro López de Ayala, su teniente adelantado, convino una tregua particular con los moros para la frontera murciana y al mismo tiempo se comprometió a dejar paso libre a huestes granadinas hacia Aragón, mantenerlas secretamente y no informar a los oriolanos. En Enero de 1457, el adelantado Pedro Fajardo hizo pregonar la obligación de no quebrantar la tregua asentada por el rey, ni hacer daño ni mal a los moros, así como "no comprar cabalgada de las vacas que aquí son traídas de tierra de moros por escuderos de Alfonso Lison, comendador de Aledo ni las que pudiera traer". Robo que tuvo inmediata contestación porque quince días después hubo alarma general cuando se supo que tres compañías de almogávares granadinos habían entrado a saltear en el campo de Cartagena. Se hizo pregón para que salieran todos los caballos y peones que quisieran para vigilar las "traviesas" y a todos ellos el Concejo ofrecía cebada para caballos y talega y calzado a los de pie [...]".

${ }^{11}$ Fuero de Andújar, tít. DCLX, p. 235

${ }^{12}$ Rodríguez Molina, José, La vida de moros y cristianos en la frontera (Alcalá la Real, Alcalá Grupo Editorial, 2007), p. 348. 
profusión sobre todo a partir del siglo XIV. Este corresponde, en Castilla, a la totalidad de los reinados de Pedro I, Enrique II, Juan I y Enrique III. Sin embargo, no es casual el hecho de que esta tregua, formalizada a partir de diversos tratados establecidos durante el período señalado se haya extendido por tanto tiempo, ya que a Muhammad V le interesaba sobremanera el mantenimiento de la paz, pues durante ese momento él se abocaba a consolidar su frontera: Priego, Iznájar, Rute, Cambil y Algeciras son plazas estratégicas que metódicamente, pasan a integrar su reino y refuerzan su frontera ${ }^{13}$.

Cuando uno de los monarcas fallecía, se estipulaba que las paces y treguas quedaban sin efecto. Por ello, cuando los nuevos monarcas estaban interesados en la continuidad de la paz, enviaban rápidamente mensajeros para que se adelantaran a la propagación de la noticia del fallecimiento del anterior monarca, solicitando y haciendo constar su propósito de mantener la paz con las condiciones estipuladas entre ambos reinos ${ }^{14}$.

3. En cuanto a su procedencia, poseemos una mayor cantidad de documentos de la cancillería castellana, a diferencia de lo que sucede con la granadina. Con respecto a su tipología, es diversa pero los tratados de paz se originaban siempre por la iniciativa de alguno de los reyes y afectaban a todo el territorio. Junto a esto, encontramos documentos que responden a tratados parciales que afectan a algunos de los sectores de la frontera y que son gestionados por nobles fronterizos ${ }^{15}$.

En relación a su contenido, Manuel García Fernández nos refiere que: "la tregua fue desde siempre una institución fronteriza tremendamente monótona, que repitió desde el siglo XIII idénticas cláusulas, todas derivadas del modelo que se establece a partir del vasallaje granadino del Pacto de Jaén de 1246, protocolos y obligaciones genéricas, a nivel siempre de estado o reino; que, sin embargo, presentó importantes cláusulas particulares, específicas de cada momento histórico que no sólo las diferencian sino que las explican" ${ }^{16}$. En general, cada tregua tenía tras de sí unos condicionantes propios y específicos que dependían de cada circunstancia histórica. Es por esto que las aspiraciones no fueron idénticas para sevillanos, cordobeses y jiennenses, sino que cada uno de ellos entendía "su paz", "su tregua", a su manera".

${ }^{13}$ Melo Carrasco, Diego, Caracteristicas y proyección de las treguas entre Castilla y Granada durante los siglos XIII, XIV y XV, en Revista de Estudios Histórico-Jurídicos, XXX (Valparaíso, 2008), pp. 277-287.

${ }^{14}$ Melo Carrasco, Diego, Características, cit. (n.13), pp. 277-287.

${ }^{15}$ Argente del Castillo Ocaña, Carmen, Las relaciones de convivencia a través de los tratados de paz, en Toro Ceballos, Francisco - Rodríguez Molina, José (coordinadores), Estudios de Frontera, Convivencia, defensa y comunicación en la frontera (Jaén, Diputación de Jaén, 2002), III, p. 84.

${ }^{16}$ García Fernández, Manuel, Las treguas entre Castilla y Granada en tiempos de Alfonso XI, 1312-1350, en Ifigea: Revista de la Sección de Geografía e Historia, 5-6 (Córdoba, 1988-1989), p. 135. Véase también: García FernándeZ, Manuel, La alteridad en la frontera de Granada (siglos XIII al XV), en GarCía FERnándeZ, Manuel, Andalucía y Granada en tiempos de los Reyes Católicos (Sevilla. Edit. Universidad de Sevilla, 2006), p. 89.

${ }^{17}$ García Fernández, Manuel, Andalucía, cit. (n. 16), p. 136. 
Pese a los esfuerzos provistos por las treguas, siempre existió un "tono de vida" que se manifestaba en cierta inseguridad, porque el peligro y la amenaza eran constante. Es por esto que resultaba extremadamente difícil impedir las incursiones de toda clase de aventureros, ya que la despoblación y la orografía facilitaban la penetración ${ }^{18}$. Con todo, la paz era respetada y anhelada ya que no solo proporcionaba seguridad sino también comprensión, olvido del pasado y de las diferencias. Paz real pues la vecindad facilitaba aquel conocimiento más íntimo entre los individuos de ambos lados, inconcebible en tiempos de guerra, y propiciaba un clima de sinceridad y comprensión fronteriza la reforzaban ${ }^{19}$.

Teniendo en cuenta lo anterior, es posible afirmar que a pesar de la compleja dinámica fronteriza, las treguas permitieron el establecimiento de unos determinados cauces de convivencia entre cristianos y musulmanes con independencia de las posibles agresiones locales aisladas. En este sentido, "racionalizaban" la vida de frontera ${ }^{20}$, haciéndola si se quiere "más humana" y menos expuesta al enfrentamiento ideológico, tal y como dan cuenta algunos aspectos menudos de la vecindad cotidiana $^{21}$, como el comercio, el pastoreo, intercambio de prendas, etc.

\section{CONTENIDO Y DISPOSICIONES DE LAS TREGUAS}

\section{Comercio y productos.}

En general, casi todos los documentos de tregua entregan un legítimo listado de aspiraciones pacíficas, que restituyen el equilibrio fronterizo concebido a partir de unas determinadas costumbres de vecindad que se arrastraban desde generaciones y en donde la diplomacia y la política, con evidente realismo, no hacían más que recoger aquello que, de costumbre, se manifestaba en ese espacio ${ }^{22}$. Lo anterior se hace patente en las distintas cláusulas que encontramos relacionadas con la convivencia mutua, manifestadas en la actividad comercial, puesto que para desarrollarla era necesario atravesar la línea de frontera, sobre todo en el caso de la ganadería. Esta situación ya quedaba fijada en el "Pacto de Jaén" de 1246, el que establecía unas determinadas circunstancias favorables para el comercio ${ }^{23}$. Sin embargo, no será hasta 1334 cuando aparezcan cláusulas específicas que fijen las condiciones del comercio ${ }^{24}$.

Este tipo de disposiciones eran importantes, especialmente para Granada, que soportaba una fuerte densidad de población y su producción de cereales, aceite de

\footnotetext{
${ }^{18}$ Torres Fontes, Juan, Dualidad, cit. (n. 4), p. 70.

${ }^{19}$ Ibíd.

${ }^{20}$ Ibíd., p. 72.

${ }^{21}$ García Fernández, Manuel, Sobre la alteridad, cit. (n. 5), p. 230.

${ }^{22}$ Rodríguez Molina, José, La vida de moros, cit. (n. 12), p. 110.

${ }^{23}$ Rodríguez Molina, José, Relaciones pacificas en la frontera con el Reino de Granada, en Segura Artero, Pedro (coordinador), Actas, cit. (n. 4), p. 264.

${ }^{24}$ Ladero Quesada, Miguel Ángel, La frontera, cit. (n. 6), p. 56.
} 
oliva $^{25}$ y ganado vacuno era claramente deficitaria ${ }^{26}$. Para suplir esta carencia, este se importaba desde el Valle del Guadalquivir. Por su parte, Granada exportaba sus productos especializados, como por ejemplo: pescado, frutos secos, azúcar y textiles de seda ${ }^{27}$. El pescado, sobre todo sardinas, se distribuía en épocas de tregua, por todo el alto y medio Guadalquivir ${ }^{28}$.

Los monarcas de ambos bandos procuraron obtener beneficios de esta actividad económica que entonces tenía cierta importancia, lo cual se manifiesta en las distintas disposiciones que aparecen en las treguas, disposiciones que, conforme pase el tiempo, se van a hacer cada vez más complejas. Con esta normativa, en opinión de Carmen Argente del Castillo Ocaña, se pretendía conseguir tres finalidades fundamentales: "promover el mejor desarrollo de la actividad, por eso siempre se incluyeron cláusulas protectoras en los distintos acuerdos de tregua o paz; impedir que salieran del reino castellano -sobre todo- determinadas mercancías, como las armas, los caballos y los cereales ${ }^{29}$; así como extraer su propia ganancia mediante un complejo sistema de impuestos que dio lugar al nacimiento de ciertas instituciones propias, dentro de las fiscalidad general del reino" ${ }^{30}$. Si

${ }^{25}$ Comenta Rodríguez Molina, José, Relaciones pacíficas, cit. (n. 4), p. 268: "El aceite, tan abundante en la actualidad en Jaén, no lo fue así en la Edad Media, en que la ciudad solía estar expuesta a carencias de este producto, como expresa el cabildo municipal al solicitar de la corona que el aceite se mantuviese libre de impuestos, dado que si ocurría lo contrario, ello sería 'cabsa que la çibdad no sea tan proveida de azeite especialmente en los años estériles, como sería no aviendo de la dicha hordenança".

${ }^{26}$ En líneas generales, se observa que los castellanos exportaban ganado, aceite, textiles de bajo precio, trayendo en contrapartida, madejas de lana y lino, frutos secos, azúcar y, sobre todo, los tejidos y prendas de seda -albornoces y almaizares, o velos, entre otros- de manufactura granadina o tunecina. Véase: LóPEz DE COCA CASTAÑER, José Enrique, Comercio exterior del reino de Granada, en Actas del II Coloquio de Historia Medieval Andaluza (Sevilla, Diputación Provincial de Sevilla, 1982), p. 375. Cfr. Peláez Rovira, Antonio, Dinamismo social en el Reino Nazarí (1454-1501): De la Granada islámica a la Granada mudéjar (Granada, Editorial Universidad de Granada, 2006), p. 422: "Una primera valoración del comercio exterior granadino permite indicar que el déficit de cereales, aceite de oliva, ganado vacuno y otros productos de primera necesidad que sufría el territorio provocó que la balanza comercial se inclinara hacia la importación de estas materias alimenticias”.

${ }^{27}$ López de Coca Castañer, José Enrique, Comercio, cit. (n. 26), p. 375.

${ }^{28}$ Ibíd., p. 375.

${ }^{29}$ En principio se excluía a los productos tradicionalmente vedados por la legislación eclesiástica y regia de Castilla como eran las armas, caballos, hierro y cereales, pero no siempre se menciona el oro y la plata que, en teoría, también lo estaban y, por otra parte, solía haber licencia limitada de saca de cereales hacia Granada para paliar la escasez habitual del emirato y permitir a sus gobernantes presentar algún aspecto positivo tras la firma de cada tregua. Véase: Ladero Quesada, Miguel Ángel, La frontera, cit. (n. 6), p. 56. Sin embargo, en opinión de López de Coca Castañer, José Enrique, La Frontera de Granada (Siglos XIII-XV): El comercio con los Infieles, Cristianos y Musulmanes en la Peninsula Ibérica: La guerra, la frontera y la convivencia (León, Fundación Sánchez Albornos, 2009), p. 374: “[...] Los testimonios que conozco revelan que el rey de Castilla permitía las sacas de trigo -y otras cosas vedadas- hacia territorio nazarí solo cuando el emir aceptaba ser su vasallo. Sucedió así con Nasr (1319), Muhammad IV (1331), Yusuf b. al-Mawl (1432) e Ismacil III (1445-1447)”.

${ }^{30}$ Argente del Castillo OCaña, Carmen, Las relaciones de convivencia, cit. (n. 15), p. 89, Véase también: Rodríguez Molina, José, Relaciones pacíficas, cit. (n. 23), p. 35; RoJAS GABRIEL, 
bien muchas de las treguas otorgan un tratamiento más bien amplio a estas cuestiones, con gran libertad de comercio, permitiendo el intercambio de productos vedados, otras veces, en cambio, los capítulos otorgan una relación mucho más restringida de productos ${ }^{31}$.

\section{Apertura de puertos secos.}

Un punto importante en toda relación comercial es aquel que se refiere a los denominados puertos secos. Debido a los ingresos que suponía el comercio tanto para cristianos como nazaríes, se hizo necesario canalizar el intercambio a través de unos puertos determinados con el fin de recoger en ellos los impuestos correspondientes y así, además, tener control sobre las mercancías vedadas ${ }^{32}$.

Las fuentes, en general, no mencionan la existencia de los "puertos" hasta fechas relativamente tardías. Según parece, la punción fiscal se ejerció a veces en ciudades y otros centros de población situados a cierta distancia de la línea fronteriza. De la misma forma, el número y localización de los "puertos” variaba en función de las circunstancias políticas por las que discurrían las relaciones castellano-granadinas, según reflejan los textos de las treguas y cuadernos de arrendamiento del diezmo y medio de lo morisco.

Manuel, La frontera entre los reinos de Sevilla y Granada en el siglo XV (1390-1481): un ensayo sobre la violencia y sus manifestaciones (Cádiz, Universidad de Cádiz, 1995), pp. 196-97. Al respecto hay testimonios que nos hablan de que casi todo era gravado: "[...] lo morisco de todos los moros e moras, esclavos o esclavas, blancos o prietos, e ganados, e otras qualesquier mercadurías que entran destos nuestros regnos para tierra de moros e salen de tierra de moros para estos nuestros regnos, asi por mar como por tierra", en PORRAS ARBOLEDAS, Pedro Andrés, El comercio fronterizo entre Andalucía y el Reino de Granada a través de sus gravámenes fiscales, en Baética: Estudios de arte, geografía e historia, 7 (Málaga, 1984), p. 248.

31 "[...] e serle ha dado saca de otro tanto ganado e aceyte como les fue dado por el Infante Don Fernando, quando ganó Antequera, por el puerto o puertos quel rey, mi señor mandare [...]", en A.H.N., Secc. "Infantado", caj. 13. Leg. $1^{\circ}$, fol 27, en AmAdOR DE LOS Ríos, José, Memoria histórico-crítica sobre las treguas celebradas en 1439 entre los reyes de Castilla y de Granada leida en varias sesiones de la Real Academia de la Historia (Madrid, Academia de la Historia, 1879), Doc. Núm. LV, pp. 109-110.

${ }^{32}$ Argente del Castillo Ocaña, Carmen, Las relaciones de convivencia, cit. (n. 15), p. 91. En el mismo sentido nos informa GonZÁLEZ JimÉNEZ, Manuel, La frontera entre Andalucía y Granada: realidades bélicas, en Ladero Quesada, Miguel Ángel (editor), La incorporación de Granada a la Corona de Castilla. Actas del Symposium Conmemorativo de Quinto Centenario (Granada, Diputación Provincial de Granada, 1993), p. 109: “Aunque en teoría la firma de las treguas permitía a los moros acceder a todos los mercados del amplio ámbito fronterizo, en la práctica y por razones de seguridad y de economía la mayor parte de las transacciones se realizaban en las propias localidades de la raya fronteriza o en lugares especialmente designados al efecto. Así, en el caso de Jaén, ciudad sobre la que disponemos de una abundante información, los almayales moros llegaban hasta la capital del reino, pero preferentemente efectuaban sus transacciones en ciertas localidades de su alfoz, como Pegalajar y Torres, o en zonas neutrales como el "Mercadillo" cercano a Cambil[...]". Complementa lo anterior García Fernández, Manuel, La Alteridad, en García Fernández, Manuel, Andalucía, cit. (n. 16), p. 231, cuando plantea: "Unos intercambios regulados por la corona castellana desde tiempos de Alfonso X el Sabio para impedir la salida de "cosas vedadas" armas, metales preciosos y caballos a través de los puertos secos: Jaén, Alcalá la Real, Antequera, Quesada, Priego, Teba, Morón de la Frontera, entre otros $[\ldots]$ ". 
Dada la posición político-militar interna a lo largo del territorio granadino, la vigilancia, la puesta en funcionamiento y el seguimiento de los puertos secos dependió, en gran medida, de la voluntad castellana, aunque la necesidad económica sirvió para que las autoridades castellanas desearan el pleno rendimiento de estos pasos naturales. Con todo, la decisión de abrirlos o cerrarlos dependía en última instancia de Castilla y de las autoridades locales castellanas ${ }^{33}$.

A modo de ejemplo, durante el período de paz que se extiende de 1418 a 1431 estuvieron abiertos los siguientes puertos: Alcalá de los Gazules en el Obispado de Cádiz; Antequera y Zahara en el Arzobispado de Sevilla; Alcalá la Real y Lucena en el Obispado de Córdoba; Jaén, Baeza, Jódar, Quesada y Huelma en la diócesis jiennense; Hellín, Mula y Lorca en la de Cartagena ${ }^{34}$. Luego, en las treguas de 1439 y 1443 , se reduce a cuatro el número de puertos: Zahara, Antequera, Alcalá la Real y Huelma ${ }^{35}$.

En relación a la importancia de los puertos secos, el que más destaca es el de Alcalá la Real, quizás por resultar el de más fácil acceso por su proximidad a Granada $^{36}$. Sin embargo, para poder confeccionar una nómina exhaustiva de los mismos, habría que recurrir a documentación de carácter fiscal, ya que las treguas siempre repiten las mismas localidades ${ }^{37}$. Por otra parte, muchas treguas restringen el desplazamiento de la población que iba a comerciar, pues es común encontrarnos con documentos que establecen un determinado límite. Por ejemplo, en el caso de los cristianos, estos podían llegar por Alcalá la Real hasta el puerto de Lope, mientras que los musulmanes podían moverse desde Alcalá la Real hasta Alcaudete. Lo anterior, probablemente con la intención de resguardar y controlar la actividad fronteriza, para lo cual recae la responsabilidad en la nobleza regional que acaparaba los principales cargos aduaneros y vigilaba el tráfico ilegal por la frontera ${ }^{38}$. Este es el caso de Luis Lucas de Torres, hijo y heredero del Condestable Miguel Lucas, quien acumulaba en su persona los cargos de alcalde mayor entre moros y cristianos y la escribanía mayor de la aduana y registros de lo morisco ${ }^{39}$.

El valor estratégico de los puertos secos, la repercusión política del control castellano y el impacto socio-económico en el territorio granadino se puede deducir del siguiente fragmento de una misiva enviada por el emir nazarí Ismacil III, que gobernaba Málaga con el apoyo de Ibn 'Abd al-Barr, a los fronteros Juan de

${ }^{33}$ Peláez Rovira, Antonio, Dinamismo social, cit. (n. 26), p. 423.

${ }^{34}$ López de Coca Castañer, José Enrique, La frontera, cit. (n. 29), p. 377.

${ }^{35}$ Ibíd., p. 378.

${ }^{36}$ Ibíd., p. 378.

${ }^{37}$ Argente del Castillo Ocaña, Carmen, Las relaciones de convivencia, cit. (n. 15), p. 91.

${ }^{38}$ García Fernández, Manuel, Sobre la alteridad, cit. (n. 5), p. 231. Esta cuestión ya queda fijada en el "Ordenamiento de sacas" dado en las Cortes de 1390, que no hacía otra cosa que recoger la situación completamente regularizada desde mediados del siglo XIV por Enrique II. De su tiempo y con autorización parecen proceder las concesiones hechas a las familias de las oligarquías ciudadanas de Córdoba, Jaén, Sevilla, Alcalá la Real y, con toda probabilidad, a Murcia, de la llamada "Renta de la exea e meajas de la correduría de los moriscos", en RoDRíGUEZ Molina, José, Relaciones pacificas, cit. (n. 23), p. 265.

${ }^{39}$ RodríGuez Molina, José, Relaciones pacificas, cit. (n. 23), p. 266. 
Cervantes y Juan Ponce de León, según documento romanceado del 23 de abril de 1450, con el objeto de cerrar el puerto de Alcalá la Real para ahogar política y económicamente a la ciudad de Granada y, de esta manera, presionar sobre el trono de Muhammad IX el Zurdo: "[...] a don Pedro de Aguilar [ frontero de Jaén] que no consienta meter mantenimientos a los moros de Granada, e, que sy no a con ellos asentado la paz gela no otorgue, e les viede (sic) los mantenimientos e cierre el puerto de Alcalá la Real [...] porque esto faziendose la dicha çibdad de Granada se le dará [... $]^{\prime 40}$.

Lo importante de este dato, es que el cierre de este puerto podía perjudicar los intereses del propio gobernante de Málaga, ya que el monarca castellano abrió este y otros puertos para dar un respiro a la economía del emergente reino centralizado en la ciudad portuaria. Este dato confirma, así, la importancia estratégica de estos pasos oficiales en el tránsito castellano-granadino ${ }^{41}$.

\section{Impuestos.}

El comercio que se realizaba a lo largo de la frontera fue objeto de una compleja legislación fiscal, que provenía de ambas cancillerías y que tenía por finalidad extraer todas las ganancias posibles de la actividad que allí se generaba. Sin embargo, en las cartas de tregua no se explica cuáles son los impuestos que se cobraran en dichas transacciones y solo hablan, generalmente, de "derechos acostumbrados". Por eso mismo, se hace necesario recurrir a otro tipo de fuentes que especifiquen cuál es el entramado de cargas impositivas que recaía sobre las mercancías ${ }^{42}$.

Es a partir de ellas cómo conocemos la existencia del magrán granadino, equivalente al $10 \%$ de todos los artículos que salían o entraban del reino nazarí. Aunque como lo ha hecho ver Pedro Porras, en algunas zonas de la frontera, en especial en tierras murcianas, existía un tributo agrícola o una capitación ${ }^{43}$. Es posible, por ejemplo, ver que en Morón se registra claramente la renta y el arancel del magrán $(1387)^{44}$, así como también en Alcalá la Real $(1476)^{45}$, donde se puede hacer un seguimiento del mismo. Los castellanos, por su parte imponían un impuesto más elevado que alcanzaba al $15 \%$ de su valor, el llamado diezmo y

${ }^{40}$ Peláez Rovira, Antonio, Dinamismo social, cit. (n. 26), p. 425 y también: Abellán Pérez, Juan, Jerez, las treguas de 1450 y la guerra civil granadina, en LóPEZ DE CoCA CASTAÑER, José Enrique (editor), Estudios sobre Málaga y el Reino de Granada en el V Centenario de la Conquista (Málaga, 1987), p. 11.

${ }^{41}$ Abellán Pérez, Juan, Jerez, en López de Coca Castañer, José Enrique (editor), Estudios, cit. (n.40), p. 11.

${ }^{42}$ Ibíd., p. 92.

${ }^{43}$ Porras Arboleda, Pedro Andrés, El comercio entre Andalucía, cit. (n. 30), p. 245. Este impuesto parece que adoptaba otra forma en la frontera murciano-granadina, ya que en esta región se gravaba el tránsito con un tributo agrícola o por capitación. Véase: PORRAS ARBOLEDA, Pedro Andrés, La presión fiscal en el Reino de Murcia al término de la Edad Media, en Historia de la Hacienda Española (épocas antigua y medieval), Homenaje al Profesor García de Valdeavellano (Madrid, Instituto de Estudios Fiscales. Ministerio de Hacienda, 1982), p. 758

${ }^{44}$ GonZÁleZ JiméneZ, Manuel, Morón de la frontera a comienzos del siglo XV, en Anuario de Estudios Medievales, 17 (Barcelona, 1987), p. 409.

${ }^{45}$ Archivo Histórico Municipal de Jaén, Actas de 1476, fol. 37v -38r. en: Porras ArboledA, Pedro Andrés, El comercio entre Andalucía, cit. (n. 30), p. 266. 
medio de lo morisco ${ }^{46}$, el cual se cobraba en diferentes puertos, revistiendo especial notoriedad en Alcalá la Real por su cuantía ${ }^{47}$. Este tributo debía pagarse por los productos de los reinos de Castilla destinados a tierra de moros y a la inversa; tal y como las otras rentas reales, se arrendaba para su recaudación ${ }^{48}$, que se hacía dividiendo el sector fronterizo según las demarcaciones eclesiásticas: el Arzobispado de Sevilla, con los obispados de Cádiz, Córdoba y Jaén, además del reino de Murcia y el Obispado de Cartagena ${ }^{49}$.

La ciudad de Jaén custodiaba el paso del Guadalbullón, que ponía en contacto

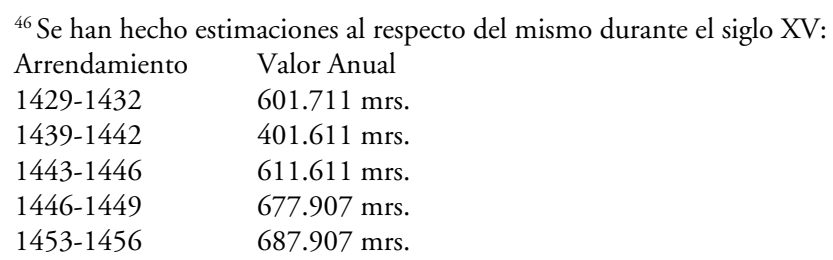

En Ladero Quesada, Miguel Ángel, Almojarifazgo sevillano y comercio exterior de Andalucía en el siglo XV, en Anuario de Historia Económica y social, 2 (Madrid, 1969), p. 99.

47 "Este día por quanto ay cierto debate y questión entre Ferrando de Torres [en nombre] del señor don Luis de Torres, Alcalde Mayor entre Christianos y moros, e Johan del Cereso, sobre los derechos del Escrivania e Registro de lo morisco, que es del dicho señor don Luis de Torres, y sobre los derechos que pertenesçien al dicho Cereso, los dichos señores mandaron y dieron cargo al corregidor Sancho de la Peña e a los veedores, junto con los letrados de esta çibdad que lo vean e determinen".

"Este dia ante los dichos señores Ferrand de Torres, en nombre del señor don Luis de Torres, Alcalde Mayor entre christianos e moros e Escrivania Mayor del Registro de lo morisco y Aduana, $e$ presento una copia de los derechos que en el puerto de la çibdad de Alcalá la Real se acostunbro levar el escribano del registro de lo morisco, su thenor de la quel e este que se sigue:

"Primeramente, de cada manada de ganado menudo, de veinte cabeças arriba, quatro maravedis.

De cada manada de ganado vacuno, de diez cabeças arriba, ocho maravedís.

De cada pieça de paño, quatro maravedís.

De cada pieça de fresa, tres mrs.

De cada capus, dos mrs.

De un sayo o un par de calças, un $\mathrm{mr}$.

De cada carga de sardina u otro pescado, quatro mrs.

De cada libra de seda, un $m r$.

De cada arroba de lino, un $\mathrm{mr}$.

De cada arroba de almendra o açucar, un $\mathrm{mr}$.

De cada arroba de pasa, cinco dineros.

De cada albo[xxaos], cinco mrs.

De cada almaysar o toca, un $\mathrm{mr}$.

De cada vara de seda, dos mrs.

De cada moro mercader almayal, de su salida, cada ves que va con su mercaduría, ocho mrs.

Del azeite o miel que se non se acostonbro levar derecho de registro dello", en A.H.M.J, Actas de 1476, fols. 37v. 38r., en RodríGuez Molina, José, Relaciones pacíficas, cit. (n. 23), p. 100.

${ }^{48}$ En 1479 Diego Hurtado de Mendoza, del Consejo de los Reyes, es el alcalde mayor del diezmo y medio de lo morisco en Andalucía y, como el resto de los altos dignatarios de la Hacienda Real Regia en Castilla, cuenta con diferentes subarrendatarios, instalados en los distintos segmentos fronterizos. Véase: Rodríguez MolinA, José, La vida de moros, cit. (n. 12), p. 242.

${ }^{49}$ FernÁNDEZ ARribas, Elena, Un aspecto de las relaciones comerciales entre Castilla y Granada: El diezmo y medio de lo morisco en la segunda mitad del siglo XV, en Historia, Instituciones y Documentos, 13 (Sevilla, 1986), p. 45. 
el valle del Guadalquivir con la Vega de Granada. Como era una ruta importante, tenía varios puertos: Cambil, Arenas, Pegalajar y Puerto de la Estrella. Para recompensar las tareas de vigilancia de las que el concejo era responsable, se le permitía retener una parte, el $5 \%$ del valor de los géneros ${ }^{50}$; esto era lo que las fuentes denominan medio diezmo de lo morisco ${ }^{51}$.

$\mathrm{El}$ análisis del diezmo y medio diezmo de lo morisco permite observar la importancia que el comercio tenía para el reino nazarí, al menos en lo que muestran los documentos conservados ${ }^{52}$. Igualmente, el seguimiento de este impuesto permite encontrar ámbitos fronterizos donde la balanza comercial era negativa para la economía granadina pero que, grosso modo, permitía el desarrollo de cierto dinamismo socio-económico derivado de las transacciones comerciales ${ }^{53}$.

Por último, otra contribución que se manifiesta en la documentación y era cobrada por los castellanos se refiere a la "ejea”, "meaja”, "correduría” y "algarfa de lo morisco". Al parecer, era un impuesto que gravaba los ingresos que se obtenían tanto por el rescate de cautivos como por las posibles ventas que ellos también realizaban ${ }^{54}$. La "renta de la exea e meaja" ${ }^{55}$, queda registrada en Alcalá la Real, en 1492. Esta renta aparece concedida por los reyes a un determinado miembro de su entorno, que conservó ese derecho de por vida y pudo transmitirlo hereditariamente ${ }^{56}$.

En el registro de los aranceles cobrados, estos eran anotados por el "escribano del registro de la aduana" y gracias a ellos se han podido estudiar los beneficios que se extraían a partir de la importante cuantía obtenida por los gravámenes fronterizos. Todo esto provocó que la titularidad de esta renta fuera disputada por miembros destacados de la nobleza castellana. Desgraciadamente, todos estos

\footnotetext{
${ }^{50}$ En general los castellanos, sin importar su nivel social, apreciaban y veían con buenos ojos los paños, las telas y paños moriscos, sobre todo para el culto litúrgico. Véase: GARCía FerNÁNDEZ, Manuel, La Alteridad, cit. (n. 5), p. 231

${ }^{51}$ Argente del Castillo Ocaña, Carmen, Las relaciones de convivencia, cit. (n.15), p. 93.

${ }^{52}$ López de Coca y CASTAN̄er, José Enrique, El reino nazarí de Granada y los medievalistas españoles: Un balance provisional, en La historia medieval en España: un balance historiográfico (1968-1998): XXV Semana de Estudios Medievales (Estella, 1998-1999), p. 152.

${ }^{53}$ Peláez Rovira, Antonio, Dinamismo social, cit. (n. 26), p. 425.

${ }^{54}$ Argente del Castillo Ocaña, Carmen, Las relaciones de convivencia, cit. (n. 15), p. 94.

${ }^{55}$ Moneda de vellón que valía la sexta parte de un dinero. Véase: EL comercio y la industria de la seda en Alcalá la Real, en Toro Ceballos, Francisco, Rodríguez Molina, José (coordinadores), Estudios de Frontera, cit. (n. 15), III, p. 634.

${ }^{56}$ Rodríguez Molina, José, La vida de moros, cit. (n. 12), p. 239. Un ejemplo de lo anterior es el que expresa Alonso Díaz de Vargas, camarero que había sido de Enrique II: "[...] Mando a Ruy Diaz, fijo legitimo... toda la renta mía de la exea e meajas de la correduría que pertenece a lo morisco desta dicha çibdad de Córdova e de todas las villas e logares de su término e obispado, con todos los derechos que a la dicha renta pertenecen e pertenesçer deven en qualquier manera, por juro de heredad, para siempre jamás, sigund que en los tienpos pasados e agora fasta aqui lo he yo poseido e poseo e recabdo e lievo, e sigund mejor e más conplidamente en la merçed e donación que dicho señor el rey, que Dios perdone, me fizo de la dicha renta, firmada por nuestro señor el rey, que Dios mantenga, e por los reyes don Juan, su abuelo e don Enrique, su padre, que Dios perdone", en: A.R.CH.G, C. 512, L. 2.370, p.1, en: Rodríguez Molina, José, La vida de moros, cit. (n. 12), p. 240
} 
datos faltan en el sector granadino, aunque se podría afirmar que la autoridad supra-local de carácter estatal que controlaba una franja fronteriza determinada sería la encargada de fiscalizar las transacciones comerciales y la receptora de los tributos aduaneros ${ }^{57}$.

\section{Actividades pecuarias.}

Debido al uso que se le daba a las tierras limítrofes y al carácter que revestía el ganado como riqueza semoviente, su situación se tornaba compleja cuando se ejercía violencia fronteriza comandada por almogávares. Por lo mismo, los tratados de tregua establecieron disposiciones que velaban por la seguridad de los rebaños de uno y otro bando, pues existía una costumbre, que venía desde antiguo, en relación con el paso de los rebaños cristianos y musulmanes a tierra de su contrario, donde pastaban cuando se vivía momentos de paz ${ }^{58}$.

Sobre esta situación hay noticias más o menos pormenorizadas contenidas en los fueros de la "familia" de fueros similares al de Cuenca, pasando por los de comienzos del siglo XIV -1305- en que los ganaderos de Jaén deben ser autorizados por Fernando IV para acotar sus propias dehesas por haber quedado privados, a causa de la guerra, de la posibilidad de llevar sus ganados a tierras de moros ${ }^{59}$.

En cuanto al uso, el pasto se utilizaba en forma restringida para los ganados que podían desplazarse desde su lugar de origen y volver en un solo día. En el caso granadino, esta práctica se afirmaba en una argumentación basada en la doctrina malikí que establecía esta premisa para el aprovechamiento de los campos con un fin ganadero ${ }^{60}$.

Los procedimientos mediante los cuales los ganados entraban a pastar en territorio enemigo no fueron siempre los mismos, pues variaron dependiendo de la coyuntura, pero en general se reconocen dos modalidades básicas: la utilización mancomunada y gratuita de las hierbas limítrofes, o su arrendamiento. Sobre esto último, baste decir que no sólo se arrendaban pastos, sino que también se tomaban rentas de labor por parte de los campesinos musulmanes ${ }^{61}$.

\footnotetext{
${ }^{57}$ Peláez Rovira, Antonio, Dinamismo social, cit. (n. 26), pp. 424-425.

${ }^{58}$ Argente del Castillo Ocaña, Carmen, Las relaciones de convivencia, cit. (n. 15), p. 98.

${ }^{59}$ Rodríguez Molina, José, Relaciones pacificas, cit. (n. 23), p. 272. Confróntese con la afirmación de ARgente del CASTillo Ocaña, Las relaciones de convivencia, cit. (n. 15), p. 98, quien establece: "En estos espacios los concejos disponían la reglamentación del uso que había de hacer sobre ellos, pero el rey podía modificarla porque sobre ellos poseía el "dominio eminente".

${ }^{60}$ Argente del Castillo OcaÑa, Carmen, Los aprovechamientos pastoriles en la frontera granadina, en CABRERA MuÑoz, Emilio (Coordinador), Andalucia entre oriente y occidente (1236-1492): Actas del V Coloquio Internacional de Historia Medieval de Andalucia (Córdoba, Diputación de Córdoba, 1988), pp. 271-280.

${ }_{11}$ "[...] E que puestos que algunos moros labrasen en el dicho término de Bexix, dezía que labrarian e labraron las tierras y heredades particulares que alli tenían, como unos labraban las heredades que tienen en término alguno, mas no las labrarian nin avian labrado por respecto que el dicho término de Bexix oviese sido de los dichos lugares de Canbil e Alhabar", en RODRígUEZ Molina, José (director), Colección diplomática del Archivo histórico municipal de Jaén: siglos XIV yXV (Jaén, Ayuntamiento de Jaén, 1985), p. 258. Véase: tb. "[...] E que al tiempo de la dicha villa de Huelma e los dichos lugares de Canbil e Alhabar eran de moros, la dicha villa de Huelma
} 
Con todo, existe un vacío en torno a los pormenores de estas prácticas pues faltan documentos de arrendamiento en los archivos, debido a que los musulmanes hacían sus contratos de forma verbal ${ }^{62}$, de manera que conocemos su existencia y muchos de sus detalles por los testimonios emitidos por los testigos de los pleitos: ganados de cristianos en Casares y en la Matabegid (Cambil, Jaén) y a la inversa, ganados de los nazaríes en Sierra Morena ${ }^{63}$.

En cuanto al territorio que cubrían estos pastos de uso mutuo, se sabe que en el siglo XIV existía "franja intermedia de ciertas proporciones", entre un cuarto y dos leguas de ancho, a lo largo de la frontera jiennense, desde Alcalá la Real hasta Cazorla. Esta era una especie de "zona neutral", donde era posible el pasto común en tiempo de treguas: son los entredichos, mencionados en documentos del siglo $\mathrm{XVI}^{64}$, cuyo origen habría que buscarlo, por lo que parece, en una sentencia conjunta de dos alcaldes entre moros y cristianos, Diego Fernández de Córdoba y Muhammad al-Handum, dada en 1417. La situación guarda semejanza con

poseía el dicho término de Bexix pacificamente, e prendaban a todos los vecinos de Canbil e Alhabar que tomavan paçiendo e roçando o caçando dentro del dicho término y ellos le pagavan las prendas llananamente./ Lo otro, porque después de ganada la dicha villa de Huelma de christianos, los señores e alcaides de la dicha cilla de Huelma, e otros por su mandado, avian prendado e prendaban a los moros vecinos del dicho lugar de Canbil el Alhavar, quando los tomaban paçiendo e roçando o caçando dentro del dicho término, en el tiempo que avía tregua entre los moros e christianos, $e$ puestos que algunos moros labrasen las tierras heredades que tienen en término alguno, mas non las labrarían nin avian labrado por respeto que el dicho término de Bexis oviese seído de los dichos lugares de Canbil e Alhavar [...]", en Rodríguez Molina, José (director), Colección diplomática, cit. (n. 61), p. 332.

${ }^{62}$ Rojas Gabriel, Manuel, La frontera, cit. (n. 30), p. 202, n.95

${ }^{63}$ Rodríguez Molina, José, Relaciones pacíficas, cit. (n. 23), p. 39. Un contrapunto nos presenta María Jesús Viguera Molins, Guerra y Paz en la Frontera Nazari desde las fuentes árabes, en Segura Artero, Pedro (coordinador), Actas del Congreso, cit. (n.4), p. 84. al afirmar que: "[...] casi inédita se halla una preciosa referencia contenida en una carta escrita por el secretario Ahmad al-Balawi: en su carta ${ }^{\circ} 11$, el gobernador almohade de Sevilla, ya a principios del siglo XII -con lo cual se manifestarían los precedentes continuados luego en la etapa nazarí- comunica al Califa el levantamiento de un insurgente en su territorio, que ataca a los musulmanes y a cristianos, apresando por ejemplo a 21 pastores cristianos que estaban confiados en la tregua vigente. El gobernador de Sevilla había detenido al insurgente y liberado a los apresados, por temor a represalias fronterizas y a la ruptura de tregua: los cristianos, al advertir cómo los musulmanes velaban por la paz, lo celebraron, decididos a salvaguardarla con más firmeza. Y el texto manifiesta como llegaban a juntarse los cristianos y los musulmanes, y los ganados de los primeros con los de los segundos: y todos en estos lugares están juntos, pastoreando en los mismos pastos".

64 "[...] y el ganado que obiese de yr a Montexicar e a Güelma desde Villagordo, Arroyovil arriba, a dar al carril, ydende el carril a Cambil e Albuniel, por el camino real a dar a Montexicar, e por estos dichos lugares, los dichos ganados pueden bien yr gozando de agua y pastos, sin menos perjuyzio desta ciudad y vecinos della, porque he sido informado que antiguamente los dichos ganados yvan y passavan por estos dichos lugares [...]", en: Toro Ceballos, Francisco, Rodríguez Molina, José (coordinadores), Estudios de Frontera, cit. (n. 15), III, pp. 517-518. Un resumen reciente sobre los "entredichos" puede consultarse en OLMO LÓPEZ, Antonio, El territorio: geografía y poblamiento del Jaén islámico en época nazarí, en VIDAL CASTRO, Francisco (editor y coordinador), Jaén en época de los nazaries (al-Andalus, S. XIII-XV), Estudios de Historia y Patrimonio Islámico y Cristiano (Alcalá la Real, Zumaque, 2010), pp. 73-105, pp. 141-172, y pp. 166-168. 
la de otras zonas de frontera donde se había regulado el pasto en común bajo el control de los municipios colindantes ${ }^{65}$.

El arrendamiento de pastos en las comarcas cercanas a la franja fronteriza y el comercio ilegal no fiscalizado no significaba que los hatos castellanos pudiesen campar con libertad al margen de las disposiciones legales aduaneras y de los acuerdos de carácter local. De hecho, el interés de la población local por beneficiarse económicamente de este negocio, al margen del gravamen que pudiese recoger la autoridad granadina pertinente, puede estar detrás de las numerosas denuncias registradas en las actas municipales castellanas de este período. Esto explicaría algunos de los acuerdos concertados por los habitantes de la frontera para que los ganados castellanos pastasen en sus tierras, ya que su beneficio consistía en eludir al fisco granadino al disminuir la cabaña ganadera propia como se ha podido documentar en la región rondeña ${ }^{66}$.

\section{Mercaderes.}

Las treguas establecen disposiciones especiales para el libre tránsito de los tratantes durante el período de paz, otorgando facilidades de intercambio para los mercaderes, lo cual aparece establecido en fórmulas como la siguiente: “[...] que sean abiertos los puertos a exeas acostumbrados para los mercaderes e almayales $e$ merchantes, christianos e moros e judios, de amas las partes, que puedan andar e venir con sus ganados e mercaderías e los dichos reynos de Castilla e de León al dicho vuestro reyno de Granada, e de vuestros reynos a los dichos reynos según lo acostumbrado en los otros tiempos de paz, e que paguen los derechos acostumbrados y que todos ellos sean seguros $[\ldots] "$... 67 .

La tipología de personajes que llevan a cabo este comercio es bastante amplia, puesto que en las treguas es común ver disposiciones otorgando facilidades de intercambio para "mercaderes, merchantes e almayales christianos e moros e judíos, de anbas partes" ${ }^{68}$. El mercader es aquel comerciante considerado en su acepción más general; el merchante era el comerciante o vendedor que no poseía una tienda fija o establecida ${ }^{69}$. En el caso de los denominados almayales, su identificación se relaciona con la voz al-mayyar que hace referencia a la acción de arriar, trajinar o dedicarse al corso ${ }^{70}$. En este sentido se entiende que son aquellos que transportan y comercializan mercancías en la frontera.

Este término fue adoptado por los castellanos y en la documentación andaluza aparece como el mercader característico de la frontera, muy presente en los momentos que se debía negociar una tregua. Su aparición en la línea fronteriza

${ }^{65}$ Ladero Quesada, Miguel Ángel, La frontera, cit. (n. 6), p. 57.

${ }^{66}$ Acién Almasa, Manuel, Ronda y su serranía en tiempos de los Reyes Católicos (Málaga, 1979), p. 137-138.

${ }^{67}$ 1472, Enero 18. Granada, en Rodríguez Molina, José, La vida de moros, cit. (n. 12), p. 408.

${ }^{68}$ Rodríguez Molina, José., La vida de moros, cit. (n. 12), p. 245.

${ }^{69}$ Peláez Rovira, Antonio, Dinamismo social, cit. (n. 26), p. 421.

${ }^{70}$ De la Granja, Fernando, Un arabismo inédito: almayarlalmayal, en Al-Andalus, 38 (1973), pp. 483-490. 
era constante, a tal punto que las autoridades de algunos concejos les señalaron ciertos días de la semana para que hicieran su camino con ciertas garantías de seguridad $^{71}$.

El almayal aparece constantemente en los textos de tregua y su circulación y seguridad en caminos, puertos y mercados contó siempre con las atenciones de los concejos fronterizos, como por ejemplo Jaén. Esto se manifiesta en la siguiente carta de seguro: "[...] mandaron dar carta de seguro para todos e quelesquier almayares que vienen de Granada e a los que fueren, que vayan e vengan seguros, que Jaén los asegura, porque el Alguasil Mayor de Granada, en nombre del señor rey de Granada, dio carta de Seguro [...]"72.

También, en la documentación se da cuenta de los denominados exeas (ejeas) ${ }^{73}$, término aplicado a personas que realizaban funciones comerciales y que debido a estas actividades conocían bien la realidad de la vida en las distintas comarcas fronterizas. En los siglos bajomedievales la palabra se aplicó a las personas que dirigían las recuas de los mercaderes entre Granada y Castilla, administrando justicia entre sus componentes, tal como aparece en algunos de los fueros de la familia de Cuenca Teruel ${ }^{74}$.

El oficio del ejea durante los siglos XII y XIII estuvo vinculado a las recuas, lo cual lo obligaba a conocer perfectamente el terreno para conducirlas caminos seguros a través de pasos y vericuetos poco conocidos, posibilitando que mercaderes y mercancías llegasen perfectamente y sin tropiezos a su destino sin caer en manos de partidas de almogávares de ambos lado de la frontera ${ }^{75}$.

${ }^{71}$ Argente del Castillo Ocaña, Carmen, Las relaciones de convivencia, cit. (n. 15), p. 95 : [...] que dia han de entrar los christianos almayares en Granada e los moros en Jahen, porque los moros e los christianos no se pierdan e sepan como van e como vienen [...]", en 1476, Febrero 23, Jaén. A.M.J, Actas de 1476, fol. 27v.

${ }^{72}$ A.M.J., Actas del 1476, fol. 198 v.

${ }^{73}$ La palabra "exea", que debe pronunciarse “ejea”, viene del término árabe, con artículo incorporado, al- sica "el guía, el acompañante, proveniente de la raíz verbal $s y^{c}$ que significa “acompañar, seguir”. Véase: MAíllo SALGADO, Felipe: Acerca del significado y referente del término "exea". Contribución al estudio del medievo español y al de su léxico, en Borrego NiETo, Julio y otros (editores), Philologica. Homenaje a D. Antonio Llorente (Salamanca, Univ. de Salamanca, 1989), p. 295. Por su parte, CorrIENTE, Federico, Diccionario de arabismos y voces afines en Iberorromance (Madrid, Gredos, 1999), p. 304, s. v. "eixea" y "exea", indica que la palabra exea, con ortografía no modernizada, tiene el sentido de 'explorador, guía' y procede "del and. [alusí] issí $a<\mathrm{cl}$. [ásico] si'a 'compañía', que en Alandalús parece haberse aplicado a las de los soldados que salían a la descubierta y, luego, a las de mercaderes que, para mutua protección, atravesaban juntos las peligrosas zonas de las fronteras. Posteriormente, como reflejan los datos de DCECH, ya dentro del rom., se hace sg. y designa al guía que asegura el paso de dichas zonas con mercancías. Del mismo origen, con evolución semántica, pero fonética y ortografía normales, es jea (cs.) 'tributo sobre mercancías de tierras de moros' ”.

${ }^{74}$ Por ejemplo en el Fuero de Baza (pp. 557-558): “dissese que [ésta] en arrequea, espere fasta que torne el axea [...] ca después que el axea uiniere [...] y el debdor non uinieres, el querelloso prende en casa del debdor que aya derecho o recombre su debdo", en: Roudil, Jean., El Fuero de Baza (La Haya, 1962), p. 166. El Fuero de Andújar se establece: "que treya larrequa en salvo a la yda e a la venida, ca él debe pechar todo el daño que en la rrequa aviniere [...] El axea judgue los rrecueros que se barajaren e fagan justicia en la rrequa". Véase: Fuero de Andújar, Tit. DCXXV, p. 227.

${ }^{75}$ Maíllo Salgado, Felipe, Acerca del significado, cit. (n. 73), p. 297. 
Como consecuencia de esta actividad, algunos de ellos se especializaron en la negociación de la libertad de prisioneros ${ }^{76}$. Sin embargo, también es común encontrarlos restituyendo prendas, ayudando a los vecinos de ambos lados de la frontera, ejerciendo de testigos cualificados ante la libre determinación religiosa de jóvenes y cautivos o huidos, o actuando como pregoneros de la justicia del otro lado del término y avisando los peligros a que se exponen quienes no respeten las normas establecidas en paces y treguas ${ }^{77}$. En este sentido presentaban muchas similitudes con el alfaqueque o redentor de cautivos. Sin embargo, eran diferentes ya que el ejea establecía relaciones de amistad mientras que el alfaqueque se volcaba en la redención de cautivos ${ }^{78}$. Su faceta de intermediarios en la liberación de cautivos se fue perdiendo, salvo en la Corona de Aragón y Murcia. Es por esta razón que en las Partidas su misión aparece atribuida a los alfaqueques.

En general, quienes desempeñaron este oficio fueron mozárabes o cristianos algarabiados, mudéjares o moros conversos, ya que, lógicamente, el ejercicio de su cometido requería cierto bilingüismo y tener relaciones amistosas o familiares a los dos lados de la frontera, cosa que en muchas circunstancias determinaba el éxito de su misión ${ }^{79}$.

Debido a la responsabilidad que le cabía en el exitoso paso y guía de las recuas, el ejea estaba muy bien remunerado. Su retribución consistía en el derecho a cobrar una parte de los beneficios obtenidos en la recua: el llamado exeadgo, del que el rey aragonés recibía dos partes; no así en Castilla, donde el exeadgo ordinariamente era el derecho exclusivo del ejea. Pero no solo recibía esa retribución sino que, además, poseía la facultad de exigir el exeadgo de todas aquellas mercancías que se compraban allende la frontera y que alcanzaba su vigilancia, así como el canje o rescate de prisioneros efectuado por sus buenos oficios, como se ha indicado ${ }^{80}$.

Para realizar su trabajo, portaban un salvoconducto, sobre todo en época de confrontaciones, el cual les permitía cruzar libremente la frontera. Esta circunstancia originó que se le encomendaran muchas veces tareas de mediación a nivel de autoridades locales ${ }^{81}$. En algunos casos, la preocupación de las autoridades por regular el tránsito de los mercaderes, con el objetivo de salvaguardar sus vidas y

${ }^{76}$ Argente del Castillo Ocaña, Carmen, Las relaciones, cit. (n. 15), p. 95.

${ }^{77}$ Rodríguez Molina, José, La vida de moros, cit. (n. 12), p. 335.

${ }^{78}$ Torres Fontes, Juan, Instituciones, cit. (n. 1), pp. 63-68.

${ }^{79}$ Maíllo Salgado, Felipe, Acerca del significado, cit. (n. 73), p. 298.

${ }^{80}$ Ibíd., p. 298.

${ }^{81}$ Este es el caso de lo que sucede en La Fuente de la Higuera, entre Vera y Lorca. Donde, al parecer, fueron cinco ejeas por cada uno de los lados. De sus actuaciones destaca, en primer lugar, el rescate de cautivos, después de la restitución de prendas, las ayudas a los vecinos de ambos lados de la frontera y, en algún caso excepcional, actúan como pregoneros de la justicia del otro término. Así, en 1482, dos ejeas de Lorca van a pregonar en la plaza de Vera sobre el riesgo que corrían los que se cruzasen los límites para cazar en términos que no fuera el suyo, ya que sería hechos cautivos. Véase: GARCía ANTÓN, José, Cautivos y rescates en la frontera entre Lorca y Vera en los últimos tiempos nazaries, en Homenaje al Profesor Juan Torres Fontes (Murcia, 1987), I, p. 550. 
ser fiscalizados sus bienes, llegó a extremos de cierto paternalismo que evidencia, de forma sutil, el proteccionismo del comercio en la región fronteriza ${ }^{82}$.

Por último, en la documentación del siglo XV su significado se enriquece con un matiz toponímico, pasando a designar el lugar por donde atravesaba la frontera, significado que se observa en la fórmula utilizada en alguno de los textos de avenencia cuando se decreta la libertad del comercio, que se inicia así: "[...] que sean abiertos los puertos e axeas [...]"83.

\section{Contrabando.}

Actividad consustancial e inseparable de la frontera y del comercio es el contrabando, una práctica compleja cuyo rastro resulta difícil seguir y en el que participaban, de forma ocasional, los propios mercaderes. Esta actividad representa, para las comarcas y localidades fronterizas, un modo de vida para gente de las más diversas capas sociales ${ }^{84}$.

Pese a las disposiciones establecidas en los pactos de tregua en relación con el comercio fronterizo, el contrabando seguía siendo un problema bastante extendido en la frontera. Lo anterior se debe a que éste se transformaba en unas de las principales posibilidades de aprovechamiento que ofrecía la situación fronteriza ${ }^{85}$, resultando muy difícil su control a través de los medios de los cuales se disponía.

Por otra parte, aunque las noticias al respecto son más bien parcas, algunos datos nos permiten vislumbrar una actividad fuera de la ley, como se manifiesta en las prohibiciones de la Corona tratando de impedir el tráfico con Aragón y Granada, de "caballos e potros e yeguas e potrancas e mulas e mulos para la silla e çerriles, como albarda" 86 . Aunque, en general, el tráfico afectaba a todo tipo de artículos.

En los casos de las poblaciones fronterizas, como Quesada, esta situación se vio acrecentada, generando un mayor tráfico clandestino, el cual es observable en la "comisión y poder a Diego López de Ayala y las demás justicias de Andalucía, frontera del reino de Granada, para proceder contra las personas que, amparándose en la tregua concertada con el rey de Granada, Muley Alí Buacín (Boabdil)

${ }^{82}$ Peláez Rovira, Antonio, Dinamismo social, cit. (n. 26), p. 429. Véase 1476, Enero 24: "[...] que día han de entrar los christianos almayares en Granada e los moros en Jahén, porque los moros e los christianos no se pierdan e sepan cómo van e cómo vienen [...]”, en RoDRíGUEZ MOLINA, José, La frontera de granada, siglos XIII-XV, en Toro Ceballos Francisco y Rodríguez MoliNA, José (coordinadores), Estudios de frontera: Alcalá la Real y el Arcipreste de Hita. Congreso Internacional celebrado en Alcalá la Real (Alcalá la Real, 1996), p. 525.

${ }^{83}$ Argente del Castillo Ocaña, Carmen, Las relaciones de convivencia, cit. (n. 15), p. 96.

${ }^{84}$ Pérez Gallego, Manuel, Morón y la frontera (1436-1480), en Toro Ceballos, Francisco - Rodríguez Molina, José (coordinadores), II Estudios de Frontera, actividad y vida en la frontera. Congreso celebrado en Alcalá la Real del 19 al 22 de noviembre de 1997 (Alcalá la Real, 1998), p. 405.

${ }^{85}$ Menjot, Denis, La contrabande dans la marche frontiéré murcienne au Moyen Age, en Homenaje al profesor Juan Torres Fontes (Murcia, 1987), II, p. 55.

${ }^{86}$ Rodríguez Molina, José (director), Colección diplomática, cit. (n. 61), doc. III, p. 8. 
trafican con los moros llevando al reino de Granada mercaderías vedadas, que sacan por el puerto de Quesada" ${ }^{87}$. Ejemplos como este serán comunes en los distintos puertos a lo largo de la frontera.

El tráfico no solamente consistía en armas, caballos y cereal, cuestión que además se estipulaba entre las mercancías prohibidas en las diferentes treguas, sino que se contrabandeaba todo tipo de productos, especialmente ganado. Esto obligó al establecimiento de normativas que frenaran esta actividad, aunque fueron poco efectivas. Entonces se hizo necesario realizar un registro de todos los ganados que había desde los mojones de la tierra de moros, diez leguas dentro de los reinos de Castilla, con el fin de evitar confusiones y engaños ${ }^{88}$. Es evidente que había otros productos que no podían ser comercializados, ya que eran vedados no sólo por el comercio castellano-granadino, sino por la propia ley islámica. Un caso de esto es el vino ${ }^{89}$.

En general, la frontera tendía a ser mucho más permeable en los tiempos de paz, momento en el cual los traficantes cruzaban la frontera por un "puerto" en compañía de mercaderes cristianos y vendían sus bestias a los musulmanes, volviendo a cruzarlo por otro sitio como si fueran comerciantes. Esto explica que en el 1382 el monarca sugiera a los aduaneros que obliguen a los mercaderes a entrar y salir por el mismo "puerto"

Los Reyes Católicos, por su parte, también combatieron el tráfico de cosas vedadas. Es así como el 10 de diciembre de 1478, la reina Isabel autorizó a cualquier persona que descubriera a unos contrabandistas para prenderlos y quedarse con una tercera parte de las mercancías y animales que llevaran consigo, estando obligada a declararlo ante las autoridades judiciales del lugar en el que se cometiera el delito siempre que fuera realengo y no de señorío. Otro tercio de las mercaderías quedaría reservado para las autoridades que entiendan en el caso ${ }^{91}$.

\footnotetext{
${ }^{87}$ Carriazo y Arroquia, Juan de Mata, Colección Diplomática de Quesada (Jaén, Instituto de Estudios Giennenses, 1975), p. xvi.

${ }^{88}$ Rodríguez Molina, José (director), Colección diplomática, cit. (n. 61), doc. 44. Juan I ordenó, en 1380 a todos los animales que estuvieran a menos de doce leguas de la frontera, haciendo contar su edad, alzada, color, etc. Véase López de CoCa y Castañer, José Enrique, El reino nazarí, cit. (n. 52), p. 386.

${ }^{89}$ Enrique IV autoriza al concejo de Jerez a sacar hasta 1500 arrobas de vino para aprovisionar a la gente de Estepona, con fecha 15 de febrero de 1457, ya que: "[...] la dicha villa esta en grand mengua de vino por cabssa de estar vedada la saca dello en esa dicha çibdad e su tierra e villas e lugares de su comarca, para lo cual e por la dicha villa estar mucho çercana a la tierra de los dichos moros no puede ser proueyda ni bastecida dello [...]", ABELLÁn PéREZ, Juan, Relaciones Castellano-Nazaries. Jerez en los inicios del Reinado de Enrique IV (1454-1457) (Cádiz, 1985), doc. 10 , p. 92.

${ }^{90}$ Juan I escribe al alcalde de las sacas de Murcia el 12 de febrero de 1382, pues tiene noticias de que muchos "[...] que moran en las doce leguas de contra los mojones de Aragón e Granada que entran e pasan a los dichos regnos con caballos e roçines e mulos e mulas e yeguas e potros e otras bestias mayores de silla de albarda con mercaderías[...] Y los dueños de bestias sin mercaderías a lybrar sus negocios, e so esta cautela que pasan a vender... muchas de las bestias, e que los dueños dellas que se tornan por otros puertos escondidamente en son de mercaderes[...]”. Véase SuÁREZ FERNÁNDEZ, Luis, Juan II y la frontera de Granada (Madrid, C.S.I.C, 1954), pp. 188-89 y 418.

${ }^{91}$ SuÁreZ FernándeZ, Luis, Juan II, cit. (n. 90).
} 
Con todo y pese a las disposiciones y medidas tomadas, el contrabando será un problema no menor en la frontera, difícil de controlar aun considerando el esfuerzo de los monarcas y las cuestiones puntuales que establecen las treguas, sobre todo en relación con la reglamentación de paso a los puertos secos y capítulos en torno al intercambio fronterizo. Este tema abre una brecha, que es posible seguir trabajando en futuras investigaciones, pero no con la documentación concerniente a las treguas que pocas luces nos dan en torno a su dinámica.

\section{Vasallaje.}

A partir del Pacto de Jaén de 1246, se instauran unas relaciones de vasallaje que van a suponer el sometimiento de Granada, manifestado, principalmente, en el pago de cuantiosas parias y la prestación de "auxilium et consilium", es decir, asistir a Cortes castellanas y secundar al rey cristiano en su lucha contra los enemigos $^{92}$. Esta situación se hará patente en distintas cartas y tratados de tregua que se firmen entre Castilla y Granada, hasta la conquista de esta última por parte de los Reyes Católicos ${ }^{93}$.

Pues, como decíamos, ya en el Pacto de Jaén se estableció el pago de 150.000 maravedíes por parte de los sultanes nazaríes, que se siguieron pagando con Alfonso X. En este sentido, el tributo significaba un reconocimiento de la hegemonía de Castilla. Si se dejaba de pagar por parte de Granada, Castilla caía sobre ella reclamándolo. La paz o la tregua quedaban restañadas cuando se aceptaba y cumplía el compromiso de dicha tributación ${ }^{94}$. Pues bien, por lo menos hasta la muerte de Fernando III, en 1252, Muhammad I pagó las parias establecidas en el acuerdo y auxilió militarmente a su señor en la conquista del valle del Guadalquivir, especialmente en la anexión de lugares como Carmona, Alcalá de Guadaíra y Sevilla ${ }^{95}$.

Las parias se transformaron en un importante medio de presión por parte del gobierno de los castellanos. Es así que estas oscilaron entre las 11.000 doblas de oro anuales hasta las 13.000 de 1421; pasando por las 12.000 de las concordias de 1456 y 1457, o las 24.000, a pagar en un plazo de tres años a partir de 1439; o, por último, las 32.000, a entregar en cuatro años desde 1443. Todo esto no era, en ningún caso, una cuestión baladí pues, en el mejor de los casos, esas cantidades suponían nada menos que la cuarta o la quinta parte de los ingresos fiscales que podía generar Granada ${ }^{96}$. Por lo tanto, son las parias un elemento vinculante im-

\footnotetext{
${ }^{92}$ Ya en la Primera Crónica General se consignan las palabras que le dice Fernando III a Alfonso, poco antes de morir: "Hijo..., señor te dexo de toda la tierra de la mar acá que los moros del rey don Rodrigo de Espanna ganado auien, e en tu sennorio fica toda: la vna conquerida, la otra tributada", en MEnÉndez PIDAL, Ramón (editor), Primera Crónica General de España (Madrid, Gredos, 1977), p. 1050.

${ }^{93}$ Rodríguez Molina, José, La vida de moros, cit. (n. 23), p. 137.

${ }^{94}$ Ibíd., p. 139.

${ }^{95}$ García Fitz, Francisco, Una España musulmana, sometida y tributaria, en Historia, Instituciones, Documentos, 31 (Sevilla, 2004), p. 234.

${ }^{96}$ Pérez Castañeda, María Dolores, Las treguas y las suspensiones de hostilidades en la dinámica, en Toro Ceballos, Francisco - Rodríguez Molina, José (coordinadores), Estudios, cit. (84), II, p. 674.
} 
portante en la relación entre Castilla y Granada, de ahí que muchas de las treguas estipulan el monto de parias y, en otros casos, la forma en cómo se pagarán.

\section{Cláusulas REFeridas a la SEGURIDAD y LiberTAD DE LAS PERSONAS. INSTITUCIONES QUE GUARDAN LA PAZ}

\section{Cautivos.}

En general, casi en todos los textos existen disposiciones referentes al compromiso de respetar la libertad y la integridad de los súbditos de uno y otro lado, así como el trato que se le ha de dar al fugitivo. Esto tiene su lógica toda vez que uno de los azotes más crueles que soportaba la población de los distintos sectores fronterizos era el cautiverio, fenómeno que se hacía presente tanto en los momentos de guerra abierta como en las etapas de tregua ${ }^{97}$.

Teniendo en cuenta lo anterior, se comprende que cuando se redactaba un tratado de paz y se exigía la devolución de un número, más o menos importante, de cautivos ${ }^{98}$ fuera común que los musulmanes se negaran puesto que alegaban que se quedaban sin cautivos para la realización de canjes individuales ${ }^{99}$. Esto es debido a que cuando en una familia alguno de sus miembros caía prisionero y había que rescatarlo por medio del canje directo era, por tanto, necesario poseer un cautivo enemigo. Para ello, este último se podía comprar en los mercados de esclavos ${ }^{100} \mathrm{o}$ adquirirlo de algún particular que haya participado en alguna acción fronteriza, que, además, tenía la obligación de facilitarles la compra ${ }^{101}$.

En general, el cautiverio realizado en tiempo de treguas era considerado

${ }^{97}$ Argente del Castillo Ocaña, Carmen, Las relaciones de convivencia, cit. (n. 15), p. 84.

${ }^{98}$ Véase en especial, A.H.N., Secc. Infantado, Caj. 13. Leg. $1^{\circ}$, fol.10 v, en: Amador DE Los Ríos, José, Memoria, cit. (n. 31), Doc. Núm. LV, pp. 84-85.

99 "En quanto al Capitulo que fue escripto, en que envió desir que el rey de Granada diese todos los xristianos e xristianas que en el regno de Granada están, questo es cosa fuerte et cosa que non puede ser, et non podría ninguno faserlo, por cabsa que los moros captivos, homes e mujeres e demás, que están en el regno de Castilla, e de los cabtivos que están en el regno de Granada, están en poder de los parientes de aquellos questán en el regno de Castilla por destroques, según uso e costumbre", en A.H.N., Secc. Infantado, caj. 13. Leg $1^{\circ}$, Num. $1^{\circ}$, fol. 10 v., en AmadOR DE Los Ríos, José, Memoria, cit. (n. 31), Doc. Núm. LV, pp. 84-85.

${ }^{100}$ Véase: Porras Arboleda, Pedro Andrés, La organización militar y social en la frontera jiennense en la Edad Media, en La sociedad medieval andaluza, grupos no privilegiados. Actas del III Coloquio de Historia Medieval Andaluza (Jaén, Diputación Provincial de Jaén, 1984), p. 21. Jaén, con un puesto destacado en las relaciones de frontera, contó con una viva actividad en la redención de cautivos, como ocurrió en determinados enclaves de Murcia. Entre los diferentes modos practicados desde estos lugares, estuvo el de abastecerse por cuenta propia de cautivos para intercambiarlos por los propios. Ello dio lugar a incursiones en la tierra contraria, incluso en períodos de paz. Así lo hizo Miguel Lucas en Montefrío, y así lo intentó Diego Fajardo, quien deseaba obtener cautivos moros para poderlos canjear por treinta hombres suyos apresados en Molina Seca, cuando fue asaltado el Rey de Granada. Véase Rodríguez Molina, José, La vida de moros, cit. (n. 12), p. 87.

${ }^{101}$ Argente del Castillo Ocaña, Carmen, Las relaciones de convivencia, cit. (n. 15), p. 86. 
ilegal ${ }^{102}$ y los capturados en época de paz debían ser devueltos a su tierra por ser "de derecho como de costumbres antigua en las fronteras"103. De ahí los puntos de encuentro interfronterizos para que esos cautivos, a menudo convertidos a la otra religión, pudiesen ejercer su derecho a la libre determinación ${ }^{104}$.

Los textos de los tratados hacen referencia a que los fugitivos fuesen acogidos sin que hubiera ninguna obligación de devolverlos a donde estaban prisioneros. La única exigencia es que no podían llevarse ningún bien del lugar de procedencia, por lo que se exigía que devolvieran los objetos de valor que portaran consigo y en caso de que no llevaran nada que jurasen ellos y las gentes del lugar, por donde habían salido donde hicieron la última posada, que no lo habían dejado oculto en ningún lugar de su camino ${ }^{105}$.

En los documentos de las treguas también se contempla la evasión de personas que manejaban dinero procedente de los impuestos, por ejemplo los almojarifes ${ }^{106}$, aunque las fórmulas dan lugar a pensar en que también podía ocurrir con otros funcionarios. En relación con lo anterior, es común encontrarnos con algunas cláusulas que se refieren a la huida de personas con una posición social elevada -grande o caballero o servidor, dicen los textos-. En ese caso, era obligación del estado receptor devolverlo si su falta era susceptible de ser perdonada, para que volviera seguro a su lugar de procedencia. En caso contrario, la obligación era expulsarlo aunque no devolverlo ${ }^{107}$.

\section{Libertad religiosa.}

Los períodos de paz y de tregua producen unas relaciones más distendidas de acuerdo con la opción personal ante un determinado credo religioso por parte de gentes que fueron hechas cautivas y en tiempos de paz son reclamadas, quedando institucionalmente establecido que manifiesten libremente su propia determinación en presencia de cristianos y musulmanes, debidamente delegados para ello ${ }^{108}$.

\footnotetext{
${ }^{102}$ Argente del Castillo Ocaña, Carmen, Cautiverio y martirio de doncellas en la fronte$r a$, en Toro Ceballos, Francisco - Rodríguez Molina, José (coordinadores), IV Estudios de Frontera (Jaén, 2002), p. 45.

${ }^{103}$ Torres Fontes, Juan, Instituciones, cit. (n. 1), p. 165.

${ }^{104}$ Rodríguez Molina, José, La vida de moros, cit. (n. 12), p. 85.

${ }^{105}$ Argente del Castillo Ocaña, Carmen, Las relaciones de convivencia, cit. (n. 15), p. 88 .

106 "[...] e se algún almoxarife u otro alguno fuyere con tesoro suyo o de otro alguno de las partes del dicho señor rey a la vuestra, o de la vuestra a la suya, que le sea tomado el tesoro que levare de su mano e sea tornado a poder de cuyo fuere, e rueguen por él sy su yerro non fuere grande y sea echado a otro reyno", 1472, Enero 18, Granada, en TORRES FONTES, Juan, Las treguas con Granada de 1462 y 1463, en Hispania, 90 (Madrid, 1963), pp. 235-236.

107 "[...] e si fuere yerro cosa que lleue ruego e que torna seguro a la parte que fuyó della, e si fuere yerro cosa que non leue ruego que sea echado del regno e del señorio e otra parte", en ARRIBAS PALAU, Mariano, Las treguas entre Castilla y Granada firmadas por Fernando I de Aragón (Tetuán, Centro de Estudios Marroquíes, Editora Marroquí , 1956), p. 50.

${ }^{108}$ Rodríguez Molina, José, Libre determinación religiosa en la frontera de Granada, en Toro Ceballos, Francisco y Rodríguez Molina, José (Coordinadores), Estudios, cit. (n. 84), II, p. 701.
} 
El respeto al principio de libertad en la frontera está datado, al menos, desde $1310^{109}$, pero también aparece en un tratado de 8 años firmado en $1320^{110}$. Más de un siglo después, en 1431, esta actitud de respeto a la libertad es negada ${ }^{111}$. Sin embargo, salvo esta única vez, los diferentes documentos conocidos que abordan el tema siempre defienden el principio de la libre decisión. Así ocurre en la tregua firmada en Granada el 19 de diciembre de 1455-62 ${ }^{112}$, donde se informa acerca del período de tiempo que los presuntos conversos deben permanecer en un lugar conocido donde las personas deputadas para ello puedan acudir a constatar la conversión y tratar de convencerles de la propia y natural opción religiosa ${ }^{113}$.

En general, fueron numerosos los cautivos cristianos convertidos al islam, también lo fueron los cautivos granadinos que abrazaron el cristianismo en las ciudades fronterizas de la Valle del Guadalquivir ${ }^{114}$. Por tanto, esto explica que, incluso, el Fuero de Frontera se haga cargo de la libre determinación religiosa. Este es el caso del Fuero de Carmona, en donde, en 1252, se estipula que a las mujeres de musulmanes y judíos no se las case por la fuerza ${ }^{115}$.

Lo anterior da cuenta de que nos encontramos ante un mundo complejo de muchas y contradictorias caras. Es el tiempo de la guerra, duro sin lugar a dudas,

109 "[...] Otrosi, nos prometemos a buena fe, sin mal enganno, que si a vos fuexere alguno o algunos de la nuestra tierra, que nos ayan a dar cuenta e recabdo de lo que por nos recabdaron, que nos, que los mandemos recabdar et que los tornemos a vuestro poder, et si fuere elche, quier nuestro de alguno de vuestros vasallos, que sea recabdado, todo lo que troxiere para nos lo enviar a nos o a cuyo fuere, et él que sea pregonado; et si quisiere ser cristiano que lo sea, et si quier moro que lo non tengamos en nuestra tierra et que vaya por do quier", en GIMÉNEz SOLER, Andrés, La Corona de Aragón y Granada, historia de las relaciones entre ambos reinos (Barcelona, Imprenta de la Casa Provincial de Caridad, 1908), pp. 167-169.

110 “[...] Et otrosí, si alcuno se fuxere a tierra de cristianos, quel non reciban et quel fagan tornar a su tierra saluo, ende, si viniere a ser cristiano, este mismo fagan al cristiano en que fuxere a su tierra", en Giménez Soler, Andrés, La Corona de Aragón, cit. (n. 109), pp. 212-214.

111 "[...] Otrosí, prometemos por nos e por los que después de nos vinieren e heredaden el dicho reyno, de no non consentir que ningún christiano, natural o súbdito de los reynos de nuestro señor el rey sea tornado moro en el dicho reyno de Granada". Véase: SuÁREZ FERNÁNDEZ, Luis, Juan II, cit. (n. 90), pp. 39-42.

112 “[...] E asy mismo dos moços que fueron allá, e dísteles liçençia que partiesen otro día commo fueron allá. E la costumbre de la Paz es que los abiades de tener a y diez días; por lo qual mandadlos traer Alcalá, que a Jurado el Alcayde Yuçef Abençerrax de facer prenda por ellos, sy no lo fases traer Alcalá, para que fablen con ellos allá, e después de 10 sy se quieren e yr allá, vayan en ora buena", en: JuAn Lovera, Carmen (editora), Colección diplomática medieval del Alcalá la Real (edición preparada por F. Toro Ceballos (Alcalá la Real, Jaén, Imprenta Esclavitud del Señor de la Humildad y María Santísima de los Dolores, 1988), I, doc. 78., p. 154-156.

${ }^{113}$ Juan Lovera, Carmen (editor), Colección diplomática, cit. (n. 112), p. 702-703.

${ }^{114}$ Véanse: Cabrera, Emilio, Cautivos cristianos en el reino de Granada durante la segunda mitad del siglo XV, en SEgura Graíño, Cristina (coordinador), Relaciones exteriores del Reino de Granada: IV del Coloquio de Historia Medieval Andaluza (Almería, Instituto de Estudios Almerienses, 1988), pp. 227-235; y Porras ARbOledA, Pedro Andrés, Las relaciones entre la ciudad de Jaén y el Reino de Granada. La paz y la guerra según los libros de actas de 1480 y 1488 , en Al-Qantara, 9 (Madrid, 1988), pp. 33-34.

${ }^{115}$ De Manuel y Rodríguez, Miguel, Memorias para la vida del Santo Rey Don Fernando III (Imprenta de la viuda de don J. Ibarra, 1800), pp. 541-543. 
y el tiempo de la paz, en el que ambas partes buscan el buen entendimiento y respeto a la libre determinación religiosa de unos cautivos u otros.

\section{Algunas cláusulas genéricas en relación con la paz fronteriza.}

En algunas treguas, sobre todo en el siglo XIV, es posible encontrar algunas cláusulas genéricas que tenían por finalidad solventar el problema de las agresiones mutuas, daños y perjuicios, fundamentalmente: solucionar pleitos, querellas, hurtos, robos, etc., acaecidos entre vecinos fronterizos. Estos compromisos aparecen documentados, por ejemplo, en la tregua de Fez en 1334 y, sobre todo, en la de Algeciras de 1334, pero posiblemente existían ya desde el siglo XIII. Se trataba de un conjunto de disposiciones llenas de buenas palabras e intenciones. La paz de Algeciras es la que da más datos al respecto. En este sentido, todos aquellos que se sentían agraviados o dañados por robos, hurtos, o captura de personas podían seguir el "rastro" hasta el lugar originario del mismo y demandar a los "alcaldes moros" todo aquello que previamente había sido usurpado ${ }^{116}$.

Otra cláusula genérica es aquella que pretendía la reconstrucción y reedificación de los castillos inmediatamente fronterizos, tanto por parte de Castilla como por parte de Granada, que a causa de la guerra permanecían arruinados. Se buscaba con ello la consecución de una tierra despoblada yerma, verdadera frontera geográfica, que permitiese detectar con facilidad la posible penetración enemiga e impedir su avance hacia el interior ${ }^{117}$.

\section{Instituciones destinadas a la negociación de las treguas y la preservación de la} convivencia.

En la negociación de las treguas y en la búsqueda de elementos que fueran efectivos en el "sobreseimiento" de la guerra, operaban una serie de instituciones. Todo lo anterior debido a que el fin principal de la tregua tiene que ver con la suspensión de hostilidades. Sin embargo, y dado el clima de beligerancia que se establece en la frontera, se hará necesario el establecimiento y creación de una serie de instituciones específicas destinadas a preservar la paz durante los períodos de tregua. Así entonces, conforme la situación fronteriza se torne más compleja, en función de una mayor violencia, estas instituciones tendrán una presencia más amplia en los textos de los pactos de tregua, con una detalla descripción de sus funciones, otorgando deberes y plazos. Además, muchas veces las fuentes entregan el dato certero de los negociadores, muchos de los cuales se repiten, sobre todo en el ámbito castellano en donde varias veces la tregua es negociada por nobles fronterizos a nombre del rey, o, sencillamente, a su nombre, funcionando como treguas parciales o locales.

En el caso de los diplomáticos enviados para firmar treguas, normalmente eran personas de altas dignidades y representantes reconocidos como individuos a los que respalda el reino. Sin embargo, muchas veces el resultado de las gestiones realizadas se debía al carácter nominal de los individuos puesto que un personaje,

\footnotetext{
${ }^{116}$ García Fernández, Manuel, Las treguas entre Castilla y Granada, cit. (n. 16), p. 140.
}

${ }^{117}$ Giménez Soler, Andrés, La Corona de Aragón, cit. (n. 109), pp. 213-214 y pp. 257258. 
un linaje o una familia podría decidir muchas cosas en un ambiente en donde se conocía con mucha precisión a la mayor parte de la población ${ }^{118}$.

Las formalidades para legitimar el papel del enviado, como interlocutor, variaban según la calidad del asunto, sin embargo lo habitual era la carta de creencia, poder que servía como fórmula acreditativa para legitimar reconocimiento y actuación ${ }^{119}$. Esa delegación se expresaba en la mayor parte de los contactos, como en el caso de las treguas o de los negocios fronterizos.

Las legaciones podían estar compuestas por varios individuos, condicionadas siempre por la misión que se debía cumplir. En este sentido era fundamental el manejo de la lengua y de ahí la importancia del intérprete. En las fuentes se consigna la existencia de verdaderos políglotas, como lo era el caso de algunos judíos, que debían tener un conocimiento específico y exhaustivo de qué era lo que se leía y contestaba en términos concretos.

Estos traductores o trujamanes, iban y venían arriba y abajo de la frontera ya que el carácter de su reconocimiento como interlocutores para las partes era fundamental, hecho que no admitía grandes variaciones para evitar tener que iniciar desde el comienzo el proceso de confianza para la circulación de la información $^{120}$. Así entonces, judíos o no, mercaderes, regidores o justicias, nobles, prohombres, hidalgos o abonados, la condición de mensajero fue fundamental como elemento clave para el contacto diplomático. A lo largo del análisis de los documentos, veremos, justamente, cómo muchos de los negociadores se repiten y cómo, en una extensión de la presente, se podría hacer un seguimiento de sus gestiones por medio de los documentos de tregua.

\section{Instituciones para la preservación de la paz en la frontera, reguladas en las} treguas.

a) Jueces de las querellas. Alcalde entre moros y cristianos. Como hemos comentado con anterioridad, el espacio fronterizo manifiesta esa dualidad guerra y paz. En este sentido, muchas veces, los conflictos estarán ligados a la acción de los almogávares y su acción depredatoria en la frontera. El resultado de sus incursiones era una serie de actos de violencia realizados, con toda una complicada secuela de reclamaciones. A partir de estas acciones se hizo necesaria la creación de una institución ocupada de dirimir los conflictos surgidos en tiempo de tregua entre ambas comunidades. Esta se conocerá con el nombre de jueces de las querellas, aunque más tarde toma protagonismo, ensombreciéndolos, el alcalde entre moros $y$ cristianos $^{121}$. Su existencia documentada se establece a partir del texto de las

${ }^{118}$ Ibíd., pp. 213-214 y pp. 257-258.

${ }^{119}$ Ibíd., pp. 213-214 y pp. 257-258.

${ }^{120}$ Ibíd., p. 590.

${ }^{121}$ Rodríguez Molina, José, La vida de moros, cit. (n. 12), p. 326. "Desde 1381, al menos, empezaron a ostentar los Fernández de Córdoba el cargo de Alcalde Mayores entre Moros y Cristianos, que será responsable máximo de solucionar las querellas suscitadas por los roces habidos entre unos y otros en la frontera. Aunque es en la primera mitad del siglo XV el tiempo de mayor actividad de la institución, no deja de estar vigente a finales de esta centuria”. 
treguas de 1310 en Murcia ${ }^{122}$. Sin embargo, su configuración más clara no se verifica hasta 1393, siendo Enrique II quien dio plena forma a la institución ${ }^{123}$, aunque, en opinión de Juan de Mata Carriazo, no actuaría hasta 1405 o $1406^{124}$. En el caso de Murcia, Torres Fontes cree encontrar sus antecedentes en la primera mitad del siglo XIV ${ }^{125}$, con la denominación de "Ballesteros de monte" ${ }^{126}$, y en el caso de Morón, González Jiménez lo registra entre 1420 y $1427^{127}$.

Entre las atribuciones de los jueces/alcaldes estaban: 1.- Oír las quejas, querellas y agravios de moros y cristianos, juzgándolas conforme a derecho; 2.-Todos los habitantes estaban obligados a acudir a sus emplazamientos y a entregarle cualquier persona que hubiese quebrantado la tregua; 3.- Tenía la facultad para conceder autorización para hacer prendas en territorio granadino como represalia; 4.-Todos los habitantes del reino estaban obligados a prestarle su ayuda y cumplir sus órdenes en el transcurso del ejercicio de sus funciones; 5.-Tenía autoridad para ordenar y hacer cuantas cosas considerara convenientes para la seguridad de la frontera. Había a lo largo de la frontera cuatro alcaldes mayores entre moros y cristianos,

${ }^{122}$ Quesada Quesada, Tomás, La Serrania de Mágina en la Baja Edad Media. Una frontera con el Reino Nazarí de Granada (Granada, Universidad de Granada, 1989), p. 181. Juan Torres Fontes afirma que "Surge esta institución en los años en que los reyes de Castilla interesaban mantener la paz en la frontera de Granada, y adquiere su proyección oficial con Enrique II y Juan I, monarcas cuyos problemas políticos tenían precisas orientaciones en otras direcciones, por lo que ambos pusieron todo su empeño en mantener buenas relaciones con Granada”. TORRES FONTES, Juan, Instituciones, cit. (n. 1), p. 71. "[...] otrosi, uos otorgamos de poner en la nuestra tierra que más acerca fuere de la vuestra un homme bono, con nuestro poder, que enmiende e faga enmendar las querellas que ouiere entre los de la nuestra tierra e la vuestra, sin otro detenimiento ninguno, et si asi non lo fisiesse, que uosque lo fagades saber a qualquier que fuere por nos adelantado en la frontera, et él que ponga y otros en su lugar que lo fagan faser [...]", en GIMÉNEZ Soler, Andrés, La Corona de Aragón, cit. (n. 109), p. 167-169.

${ }^{123}$ Ladero Quesada, Miguel Ángel, La frontera, cit. (n. 6), p. 55.

${ }^{124}$ Carriazo y Arroquia, Juan de Mata, Un alcalde entre los cristianos y los moros, en la frontera de. Granada, en Al-Andalus, 13 (Madrid, 1948) 1, p. 104.

${ }^{125}$ Torres Fontes, Juan, El alcalde entre Moros y cristianos del reino de Murcia, en Hispania. Revista Española De Historia, 78 (Madrid, 1960), pp. 55-80.

126 "[...] Nos el rey de Castella, e de León, e de Portugal, fazemos saber a vos, los nuestros contadores mayores, quel concejo de la cibdat de Murcia nos enviaron decir que por quanto en aquella tierra non ay omnes que sepan seguir los rastros de los almogávares de tierra de moros que entran a fazer mal e daño a los nuestros regnos salvo los vallesteros de monte, e que nos pedian por merced que franqueseamos de monedas e algunos vallesteros para seguir los rastros, E nos, entendiendo que es nuestro servicio tenermos por bien e es nuestra merced que ayan en aquella cibdat seys vallesteros de monte para seguir los dichos rastros e que sean quitos de monedas para siempre. Porque vos mandamos que les dedes vuestras cartas sobrello, quales les cunplieren, e pongades los dichos seys vallesteros en lo salvado de las nuestras rentas. E non fagades ende al por alguna manera, so pena de la nuestra merced. Fecha veynte e quatro días de enero, año del Nascimiento de Nuestro Señor Jhesucristo de mil e trezientos e ochenta e cinco años. Nos el rey”. A.M.M., Cartulario Real, 1384-1391, fol.125, en TORRES FonTES, Juan, Notas sobre los fieles del rastro y alfaqueques murcianos, en Miscelánea de Estudios Árabes y Hebreos (Granada, 1961), X, p. 92.

${ }^{127}$ GonZÁlez Jiménez, Manuel, Morón, una villa de frontera (1402-1427), en SEgura Graíño, Cristina (Coordinador), Relaciones exteriores, cit. (n. 114), p. 57. 
en el obispado de Cádiz, Sevilla, Córdoba-Jaén y Murcia ${ }^{128}$, y probablemente actuaban en pareja, musulmán y cristiano, en cada sector fronterizo ${ }^{129}$.

Sabemos que esta institución se replicó al otro lado de la frontera y se le llamo Juez entre los Reyes (al-qadi bayna l-muluk). Figura este título referido al alcalde granadino 'Ali Sacid al-Amin, secretario particular del sultán Abu 1-Hasan 'Ali y jefe de la oficina de interpretación de su cancillería, el cual ejercía también la citada magistratura el 5 de safar de $875=3$ de agosto de $1470^{130}$. Entre las atribuciones que tenía este juez estaban: "la competencia para fallar las querellas que los cristianos pudieran formular contra los granadinos por las infracciones cometidas por éstos a los tratados de treguas convenidos por ambas partes, durante la vigencia de los mismos"131. Así entonces, se desprende que el funcionamiento de ambas instituciones era similar, cumpliendo las mismas funciones grosso modo ${ }^{132}$. Como comprobación de lo anterior, tenemos el testimonio de Ibn Marzuq, juez de frontera en la zona andalusí controlada por los Benimerines (1348), quien nos comenta: "Yo mismo estuve un año encargado de distribuir los dones y de inspeccionar estos territorios y de oir las reclamaciones de sus habitantes y de comprobar que necesitaban [...] Llegué hasta Zahara (al-Sajra) y la fortaleza de Olvera y el territorio vecino, deteniéndome en la frontera entre los musulmanes y cristianos, oyendo las quejas de la gente de ambas religiones, obteniendo todos y cada uno su derecho"133.

Pese a lo anterior, pareciera ser que ninguno de los alcaldes, ni musulmanes ni cristianos, tuvieron jurisdicción sobre las rupturas de treguas ocurridas en el mar: en este caso, es de suponer que, del lado castellano, intervendría el tribunal del Almirante, con sede en Sevilla ${ }^{134}$.

En opinión de algunos autores, como el caso de Juan Torres Fontes, esta institución, al menos en el caso castellano, demostró una total ineficacia y descrédito, pues fue utilizada con marcados intereses políticos por quienes sólo estaban interesados en obtener el nombramiento por los beneficios que personalmente pudiera reportarles, todo lo que repercutió en su eficacia y actividad ${ }^{135}$. No obstante lo anterior, será común observar su existencia en los pactos de tregua así

${ }^{128}$ GonZÁlez Jiménez, Manuel, Morón, cit. (n. 128), p. 58.

${ }^{129}$ LAdero Quesada, Miguel Ángel, La frontera, cit. (n. 6), p. 56.

${ }^{130}$ SECo de LuCEnA, Luis, El Juez de frontera y los fieles del rastro, en Miscelánea de Estudios Arabes y Hebraicos (Granada, 1957), VII, p. 140.

${ }^{131}$ SeCO DE LuCEnA, Luis, El Juez de frontera, cit. (n. 130), pp. 137-141. Las fuentes son muy explicitas al hablar de su actuación: "Este día dio rasón en el cabildo de Fernando de Torres, alcalde mayor entre cristianos y moros, que él con su escribano anduvo a faser la pesquisa sobre las dos rejas e una açada que hurtaron en Canbil e no falló quién lo furto; luego los dichos señores mandaron a Fernando Rodrigues, reçebtor de los maravedies de las ynpusiçiones, que pague a Diego Byedma, alcalde de Huelma, çiento e cincuenta mrs. Para que los dé a los dichos moros de Canbil o compre otro tanto y gelo de", en Porras Arboleda, Pedro Andrés, La frontera del Reino de Granada a través del libro de actas del Cabildo de Jaén de 1476, en Al-Qantara, XIV (Madrid, 1993), p. 154.

${ }^{132}$ Sobre la actuación pormenorizada del mismo véase un ejemplo, para el caso de las comarcas de Lorca y Vera, en: ARCAs CAMPOY, María, Cadies y Alcaldes en la Frontera Oriental Nazarí (S. XV), en Al-Qantara, 20 (Madrid, 1999) 2, pp. 487-501.

${ }^{133}$ Viguera Molins, María Jesús, Guerra y Paz, cit. (n. 63), p. 85.

${ }^{134}$ Ladero Quesada, Miguel Ángel, La frontera, cit. (n. 6), p. 56.

135 Torres Fontes, Juan, Instituciones, cit. (n. 1), p. 73. 
como la regulación de su actividad y los pasos a seguir por ellos en caso de alguna reclamación. Por ejemplo, en la tregua de 1477, se estipula, entre otras cosas, que se pongan jueces entre ambas partes para que juzguen las querellas que sucedieran durante el tiempo de $\mathrm{paz}^{136}$.

En cuanto a la vigencia de la institución, según la documentación pareciera ser que se mantuvo vigente hasta que la Corona decidió prescindir de ella, encargando sus tareas a hombres de confianza, como sucedió el 17 de enero de 1478 , en que se nombran dos caballeros, uno castellano y otro musulmán para buscar, determinar y reparar los incidentes ocurridos en las treguas así como sus consecuencias, " $e$ la sentencia que estos dichos juezes dieren e averiguaren, que los dichos Reyes de Castilla e vos el alto rey de Granada estareis e pasareis por ello, para lo mandar guardar e conplir" 137.

Como hemos comentado, el oficio del alcalde entre moros y cristianos recayó en personas importantes vinculadas a la vida fronteriza. Así, en la zona cordobesa lo fueron durante largos periodos los señores de Priego y Aguilar, que además solían ser alcaldes de la gran fortaleza de Alcalá la Real; uno de ellos, Alfonso Fernández de Córdoba, ejerció el oficio durante más de cuarenta años, entre 1383 y 1424. En Murcia, existe constancia del ejercicio del cargo por Alonso Yáñez y Fajardo ya en 1378. En la zona de Sevilla se puede suponer que estaba vinculado a los Adelantados de Andalucía, o a personas relacionadas y dependientes de ellos ${ }^{138}$. Por su parte, el Sultán granadino también confió la magistratura de frontera a personajes de relieve, expertos en los asuntos de política exterior, conocedores del carácter e idiosincrasia de la parte contraria y que gozaban, entre esta, de consideración, aprecio y respetabilidad ${ }^{139}$.

A lo anterior se suma el hecho de que el cargo era retribuido y proporcionaba un sueldo, como en el caso de los Fernández de Córdoba, que oscilaba entre los 5.000 y 10.000 mrs., en los años centrales del siglo XIV. Cantidad respetable, sin duda, en esa fecha ${ }^{140}$ y que hacía de esta institución un apetecible privilegio. Todo esto confirma el hecho de que los intereses personales hayan primado sobre los colectivos en esta sociedad de relaciones tan interdependientes.

b) Los Fieles del rastro. Cuando se llevaba a cabo una algara en los límites fronterizos que llegaban a la jurisdicción de algún concejo, se ponía en marcha todo un aparataje que tenía como finalidad seguir la pista de la cosa perdida o robada, o el rastro del cautivo. Esta última misión se le encomendaba a los rastreros. Los fieles del rastro ${ }^{141}$ constituyeron una institución al servicio del juez de frontera, una

${ }^{136}$ Perea Carpio, Carmen, La frontera concejo de Jaén-Reino de Granada en 1476, en Cuadernos de Estudios Medievales, 10-11 (Granada, 1983), pp. 235-236.

${ }^{137}$ Carriazo Arroquía, Juan de Mata, En la frontera, cit. (n. 2), pp. 232-234.

${ }^{138}$ Ladero Quesada, Miguel Ángel, La frontera, cit. (n. 6), p. 56.

${ }^{139}$ Seco de Lucena, Luis, El Juez de frontera, cit. (n. 130), p. 140.

${ }^{140}$ Quintanilla Raso, María Concepción, El señorío de la Casa de Aguilar, en Torres Delgado, Cristóbal (Coordinador), Andalucía Medieval: Nuevos estudios (Córdoba, Monte de Piedad y Caja de Ahorro de Córdoba, 1979), pp. 61-64.

${ }^{141}$ Entre las condiciones que debían poseer los fieles de rastro, encontramos: juventud, fuerza física, resistencia, conocimiento de terreno, de sus aguas y zonas de paso "las traviesas". Quintanilla Raso, María Concepción, El señorio, cit. (n. 140), p. 93. 
suerte de "policía fronteriza"142, que se encargaba de seguir las huellas del presunto delincuente, hasta encontrarlo. En general, constituyen una corporación cerrada de individuos nombrados, instruidos y juramentados, siendo ante todo un oficio concejil. Son muy pocos los detalles que tenemos en torno a su organización y los que hay son los referentes a la corporación de fieles del rastro del Concejo de Jaén que estaba constituida por 30 personas ${ }^{143}$.

Sus servicios no eran demandados solamente por los alcaldes entre moros y cristianos, sino también por los alcaldes mayores de la frontera. En este sentido, no solo se circunscribían a la persecución de quienes quebrantaban la paz con el Reino de Granada, sino que también eran empleados en la resolución de problemas similares entre cristianos; al menos en el reino de Murcia así ocurría ${ }^{144}$.

Los antecedentes más remotos de este oficio de rastrería se remontan al siglo XIV y aparece por primera vez con sus funciones delimitadas en las treguas firmadas en 1331; desde entonces, el oficio quedó constituido ${ }^{145}$. Su acción era coordinada por los alcaldes del rastro y sus actuaciones eran registradas por el escribano del rastro ${ }^{146}$.

Su modus operandi era el siguiente: cuando se cometía una violencia sobre una persona o cosa por parte de las gentes del otro lado de la frontera, los propios perjudicados, por sí mismos, o representados por su concejo, reclamaban los servicios de estos fieles del rastro, que acudían al lugar del atropello, reconocían las huellas de los atacantes y seguían su rastro hasta llegar al límite con otro concejo ${ }^{147}$. Entonces allí convocaban a las autoridades y rastreros correspondientes y les entregaban el rastro; así entonces, los que lo reciben deben responder de la violencia, a menos que el rastro pase a otro término, cuyos vecinos y rastreros lo puedan recibir, a su $v z^{148}$. Y así, continúa, hasta llegar al lugar donde se encuentra el cautivo, la cosa robada o los ladrones, que son apremiados a devolverlos o pagar una compensación. Establecida la responsabilidad de los presuntos delincuentes, el juez dictaba sentencia, que había de quedar ejecutada en el plazo de cincuenta días ${ }^{149}$.

${ }^{142}$ Torres Fontes, Juan, Notas sobre los fieles, cit. (n. 126), pp. 89-105.

${ }^{143}$ Quesada Quesada, Tomás, La Serranía, cit. (n. 122), p. 179.

${ }^{144}$ Ibíd., p. 178.

145 Torres Fontes, JuAn, El alcalde entre moros, cit. (n.124), p. 58.

${ }^{146}$ Argente del Castillo Ocaña, Carmen, Los cautivos en la frontera entre Jaén y Granada, en Segura Graíño, Cristina (coordinador), Relaciones exteriores, cit. (n. 114), pp. 19-29.

${ }^{147}$ Cfr. Porras Arboleda, Pedro Andrés, El derecho de Frontera durante la baja Edad Media. La regulación de las relaciones transfronterizas en tiempo de treguas y guerras, en Estudios dedicados a la memoria del Prof. L.M. Diez de Salazar (Bilbao, 1992), I, p. 278: "Los rastreros salían al campo en el momento en que se presentaba la correspondiente denuncia ante el municipio, pero para tomar represalias era necesaria la autorización del alcalde entre moros y cristianos".

${ }^{148}$ Quesada Quesada, Tomás, La Serranía, cit. (n. 122), p. 181; y también, Argente DeL Castillo Ocaña, Carmen, Los cautivos, cit. (n. 146), p. 219. Sólo a modo de ejemplo citaremos algunos casos: Sábado 5-VI-1479, "En sábado çinco de Junio, a ño de MCCCCLXXIX años, dieron Fernando García de galues e Miguell Miesia e Juan Sanches Dueñas, fieles del rastro que fueron a ver el rastro que troxieron los moros que troxieron en rrastro fasta la boca de val de Jetreço, a la vereda que desciende de Almaseral, que viene de la Puerta de Algar", en Quesada Quesada, Tomás, La Serrania, cit. (n. 122), p. 275.

${ }^{149}$ Un ejemplo de esto es lo que se visualiza en una carta fechada 16 de marzo de 1465 en 
En algunos casos, estos rastreros tuvieron beneficios producto del trabajo que desempeñaban. Se sabe, por ejemplo, que Juan I dio carácter oficial a los fieles del rastro de la ciudad de Murcia, otorgándoles como compensación a su dedicación y oficio una serie de beneficios económicos, como era la exención en el pago de tributos reales y concejiles, a excepción de las alcabalas. De la misma forma, se estipuló cuáles eran los requisitos que debía cumplir, a saber: conocer perfectamente el territorio de la jurisdicción concejala a que estaban adscritos y ser prácticos en el oficio de reconocer y seguir las huellas de los delincuentes ${ }^{150}$. Aparte de las franquicias, los fieles del rastro cobraban por cada rastro que seguían; en el caso del concejo de Jaén, la cantidad ascendía a 200 maravedíes ${ }^{151}$.

La localización de la mayor parte de los robos y la solución correspondiente se debió a la organización y buen hacer de los rastreros, quienes, con sus interconexiones, eran capaces de averiguar el paradero de un cautivo, el destino de una caballería o el final de una bolsa de monedas. Ellos permitieron a algunas ciudades defenderse de las acusaciones de robos puesto que su cometido consistió en esclarecer el desarrollo de los hechos desde su inicio hasta el final ${ }^{152}$.

c) Los alfaqueques. La palabra alfaqueque viene del árabe al-fakkak, que significa redentor de cautivos. Estos son, en estricto rigor, aquellos encargados de redimir a los cautivos. Su misión primordial era la de servir de intermediarios entre ambas comunidades a través del trato y el contrato que permita el rescate o canje de cautivos y conducirlos hasta lugar seguro. Otras veces su gestión no era propiamente la redención de cautivos, sino la recuperación de ganados y otras cosas robadas $^{153}$. En general, la compra o venta de cautivos suponía, además, la puesta en marcha de amplias operaciones económicas: de una parte, la entrega de dinero o fianzas efectuadas ante el escribano público; de otra, la solvencia, pero, sobre todo, la garantía de la honradez del alfaqueque, que era la base de todo el negocio en el que intervenían muchas personas, porque reunir las cantidades exigidas en los rescates para economías modestas suponía acudir a onerosos préstamos y esos

Martos, en donde Juan Docampo, comendador o alcalde de la villa de Martos por el maestre de Calatrava, a Alcalá la Real. Sobre algunos moros que ésta le reclama " $A$ lo que, sennores me escriuis de moro que yo mande entre-l gar a la çibdad, me escribieron requiriéndome que, pues el rrastro me era dado por vos otros, / carta de su requerimiento/ me enviaron una carta firmada de los nonbres de vos otros, sennores, en la qual se contiene commo vos otros, sennores, les fisistes saber que avyades entregado el rrastro de aquel moro esta villa, e commo avyades sabydo que aquel moro estaua en la villa de Porcuna e que codemandasen a la dicha villa", en JUAN LOVERA, Carmen (editora), Colección Diplomática, cit. (n. 112), p. 166.

${ }^{150}$ Torres Fontes, Juan, Instituciones, cit. (n. 1), p. 90.

${ }^{151}$ Quesada Quesada, Tomas, La Serranía, cit. (n. 122), p. 181.

${ }^{152}$ Rodríguez Molina, José, La vida de moros, cit. (n. 12), p. 331

${ }^{153}$ Dice Díaz Borrás, Andrés, El miedo al Mediterráneo: la caridad popular valenciana y la redención de cautivos bajo poder musulmán, 1323-1539 (Barcelona, Consejo Superior de Investigaciones Científicas, Institución Milá y Fontanals, 2001), p. 61: "Dentro de sus funciones se encontraba la de perseguir y evitar razzias incontroladas que de forma ilegal se sucedían en los linderos territoriales. Estas incursiones tenían por objeto, generalmente, la captura de bienes, ganados o personas. Los alfaqueques devolvían a sus dueños todo lo robado y los cautivos a sus casas". 
prestamistas eran los que se asociaban con los alfaqueques como medio eficaz para mantener sus pingües negocios ${ }^{154}$.

Según James Brodman, la práctica de la redención no fue institucionalizada hasta el siglo XII. En un principio estaba en manos de particulares e instituciones religiosas, pero pronto esta actividad se convirtió en un negocio que llamó la atención de la misma monarquía. Así entonces, durante el siglo XIII se intentó por parte de los monarcas poner orden estableciendo las competencias y las obligaciones de los alfaqueques en las Partidas y, posteriormente, en los ordenamientos de Alcalá de Henares de 1348, los Ordenamientos de Toro de 1368 y las Cortes de Toro de $1371^{155}$. En el sector de la frontera jiennense la mención más antigua referida al alfaqueque municipal data de $1341^{156}$.

Este trabajo exigía condiciones personales especiales y exposición a riesgos constantes que iban desde el robo y la violencia hasta la prisión y el asesinato. A cambio de este esfuerzo, los alfaqueques tenían derecho a indemnizaciones variables que, por lo general, están en razón directa al precio del rescate ${ }^{157}$. En caso de que la transacción fuera el intercambio de un cautivo por otro - un moro por un cristiano $^{158}$-, sin intermediar dinero alguno, se limitaba a recibir un maravedí en concepto de "panazgo", esto es, por el mantenimiento del prisionero el tiempo que durase el viaje o la negociación ${ }^{159}$.

Para el ejercicio del oficio de alfaqueque era necesario el conocimiento de la lengua del reino vecino. Muchas veces quienes lo ejercían eran tornadizos o tru-

${ }^{154}$ TORres FonTes, Juan, Instituciones, cit. (n. 1), p. 65. En general, quienes poseían cautivos querían sacar el máximo provecho, por lo que muchas veces tenían al cautivo todo el tiempo que fuese necesario, hasta que se diera curso a sus exigencias. Tenemos un contrato de redención fechado el 7 de agosto de 1486, que dice: "Los dos honorables alfaquíes Sacd b. Yahyà al-Yannaq y Muhammad b. Husayn al-Faqih, que viven en la taha de al-Yawyar (El Laujar), garantizan con su hacienda y bajo su responsabilidad, cinco ratl y medio de excelente hilo de seda laujari a los dos caballero Tarbina y Pedro de la Torre, su compañero, a cambio del rescate del cautivo Ahmad b. Ahmad al-Basti, en el término de veinte días contados a partir de la fecha[...]”, en SECO DE LuCEnA, Luis, Documentos Arábigo-Granadinos (edición crítica del texto árabe y traducción al español con introducción, notas, glosarios e índices, Madrid, Publicaciones del Instituto de Estudios Islámicos, 1961), p. 100 texto árabe (donde indica alfaqueques, no alfaquíes como aparece en la traducción), 108 traducción.

${ }^{155}$ González Arévalo, Raúl, El cautiverio en Málaga a fines de la Edad Media (Málaga. Diputación de Málaga, 2006), p. 98.

${ }^{156}$ Rodríguez Molina, José, La vida de moros, cit. (n. 12), p. 334.

${ }^{157}$ Torres Fontes, Juan, Los alfaqueques castellanos en la frontera de Granada, en Homenaje a Don Agustín Millares Carlo, Tomo (Caja Insular de Ahorros de la Gran Canaria, 1975), II, p. 100 .

${ }^{158}$ En bastantes ocasiones, no era nada de raro que los musulmanes exigiesen, en lugar del pago de un rescate, lo que se llamaba un canje "moro por cristiano", situación que obligaba a los parientes o amigos del afectado a buscar y llegar a un acuerdo con el dueño del cautivo granadino correspondiente, en TORRES FonTES, Juan, Los alfaqueques, cit. (n. 157), p. 100.

${ }^{159}$ García FITZ, FRANCISCO, ¿De Exterminandis Sarracenis? El Trato dado al enemigo musulmán en el Reino de Castilla-León durante la plena Edad Media, en Fierro, María Isabel - García Fitz, Francisco, El cuerpo derrotado: Cómo trataban musulmanes y cristianos a los enemigos vencidos (Península Ibérica, ss. VIII-XIII) (Madrid, Consejo Superior de Investigaciones Científicas, 2008), p. 14. 
jamanes. En razón de su oficio estaban dotados de inmunidad y podían entrar y salir libremente del otro reino, pudiendo incluso entrevistarse con entera libertad con los cautivos. En cuanto a su organización, las Siete Partidas (II, XXX, 1-3) establecen: "Alfaqueque tanto quiere decir en arabigo, como omes de buena verdad, que son puestos para sacar los catiuos. E éstos, según los antiguos mostraron, deuen aver en si seys cosas: la vna, que sean verdaderos, onde lleuan el nome. La segunda, sin cobdicia. La tercera, que sean sabidores también del lenguaje de aquella tierra que van como el de la suya. La quarta, que no sean malquerientes. La quinta, que sean esforzados. La sexta, que ayan algo de lo suyo" ${ }^{160}$. En relación a este, su origen lo podemos rastrear en el fuero de Teruel, otorgado en 1179, donde encontramos su primera exposición jurídica en cuanto a sus deberes y derechos. En el mismo fuero se establecía su paga en un 10\% del rescate, aunque no siempre se sabe con claridad cuál era la remuneración pagada ${ }^{161}$.

En muchas ocasiones el oficio de alfaqueque fue ejercido por personas que mantenían buenas relaciones con ambos reinos. Este era el caso de muchos judíos, ya que su misión parecía más adecuada al carácter de esta minoría ${ }^{162} \mathrm{y}$, también, el de los comerciantes italianos que acudían a Granada ${ }^{163}$. La documentación da cuenta de hombres prácticos para los tratos, conocedores del árabe, y de una habilidad extraordinaria para informarse de cuantas noticias podían ser de utilidad para los jefes cristianos de la frontera ${ }^{164}$. La existencia de esta institución se manifiesta a uno y otro lado de la frontera pues los encontramos replicados tanto en Castilla como en Granada ${ }^{165}$.

${ }^{160}$ García Fitz, Francisco, ¿De Exterminandis Sarracenis? cit. (n. 159), p. 14.

${ }^{161}$ Ferrer i Mallol, María Teresa, Els redemptors de captius: mostolafs, eixees o alfaquecs (segles XII-XIII), en Medievalia, 9 (Barcelona, Instituto Universitario de Estudios Medievales, Universitat Autónoma de Barcelona, 1990), p. 86: "Recibían su salario, como confirma la orden dada por el concejo de Jaén, en 1476, a Diego López, cambiador, para que "de e pague doscientos mrs. Al Majo, que troxo los dos christianos que faltavan de Huelma", en GarRIDO AgUILAR, Juan Carlos, Relaciones fronterizas con el reino de Granada en las capitulaciones del Archivo Histórico Municipal de Jaén, en: Segura Graíño, Cristina (editora), Relaciones exteriores, cit. (n.114), pp. 168-169.

${ }^{162}$ Torres Fontes, Juan, Notas sobre los fieles, cit. (n. 126), p. 103.

${ }^{163}$ Quesada Quesada, Tomás, La Serranía, cit. (n. 122), p. 177. Cfr. Borrás, Miedo, cit., p. 64: "Los alfaqueques, no obligatoriamente debieron ser cristianos, encontramos judíos y también moros realizando estas funciones, hecho que no constituía sorpresa alguna, especialmente si se trataba de gente dotada para el comercio y el beneficio". También es importante constatar la existencia de estos mercaderes, especialmente genoveses, cuya presencia está documentada: "[...] A intercesión de Juan de Benavides e del arcediano de Ubeda mandaron dar carta de seguro miçer Lucia e miçer Bartolomé, ginoveses, que vengan de Granada a esta çibdad a dar orden sobre la deliberación de una fija de Juan de Benavides que está en Granada", en CARRIAZO y ARroqUiA, Juan de Mata, En la Frontera, cit. (n. 2), p. 257.

${ }^{164}$ Torres Fontes, Juan, Los alfaqueques, cit. (n. 157), p. 103. TORres Fontes, Juan, Instituciones, cit. (n. 1), p. 67, sintetiza las capacidades que debía tener un Alfaqueque en las siguientes: conocimiento de varias lenguas; capacidad para el trato y discusión; habilidad para ganar amigos y obtener información precisa, ya que era frecuente que el alfaqueque fuera el espía más aprovechable y quien mejor conociera los preparativos o simplemente los propósitos militares que pudieran producirse en los territorios vecinos que visitaba”.

${ }^{165}$ Díaz Borrás, Andrés, El miedo al Mediterráneo, cit. (n. 153), p. 62: "también los alfa- 
Para el cumplimiento de su oficio, el alfaqueque portaba, además de una carta de seguro de la ciudad o autoridad del territorio que visita, un pendoncillo de color que indicaba el concejo del cual prevenía o de quien dependía. Los alfaqueques que entraban a los territorio del reino de Granada obtenían un permiso llamado $a m a n^{166}$, que era, en rigor, un salvoconducto ${ }^{167}$.Para evitar la sorpresa y la confusión, era común que en su viaje transitaran por el camino real o lugares fijados en las bases preliminares de los acuerdos. Sin embargo, estas cartas y señas no evitaban que los alfaqueques sufrieran el robo de sus pertenencias e, incluso, la prisión ${ }^{168}$.

Según se deja entrever en la documentación, existía un buen número de alfaqueques "menores", tanto granadinos como cristianos; respecto a estos últimos se ha señalado que, a veces, se vestían y dejaban crecer barba como musulmanes para ser mejor aceptados en el ejercicio de su actividad ${ }^{169}$. La existencia de estos se debe, en gran parte, a que el oficio era rentable, en la medida de la gran cantidad de cautivos existentes y los rescates que por ello se pagaban. Esto, independientemente de que el alfaqueque pudiese fallar en su cometido y que, por lo tanto, obligara a negociaciones entre ciudades ${ }^{170}$.

Así, con el tiempo, esta institución se hará cada vez más rentable, debido al constante intercambio y rescate de cautivos a nivel de la frontera. Todo esto obligará a la Corona de Castilla a reglamentar la institución por medio del

queques musulmanes tuvieron una destacada participación en la redención de los apresados musulmanes en poder de cristianos. De ellos sabemos muy poco y entra de lleno en el tema de cautivos musulmanes redimidos por sus correligionarios; de cualquier manera tenemos constancia de su existencia. El padre Faustino Gazulla decía al respecto es de creer que serían éstos los que designaban con el nombre de alhaqueques, palabra árabe que significa redentores y la misma palabra adoptó Castilla para distinguir a los que ejercían esta misión de redimir cautivos".

${ }^{166} \mathrm{El} 6$ de julio de 1484, Abu l-Hasan 'Ali, entrega el siguiente salvoconducto al vecino de Bornos Hernando de Figueroa: "Las loores a sólo Dios. Por orden y mandato del belicoso afamado Hamet, rey y ensalzador de la ley de la salvación, a quien Dios esfuerce y ayude mediante su gracia. Se concede mediante ella este real seguro al cristiano virtuoso, nombrado, caritativo, de buenos respetos y aprobada vida e costumbre, de noble, limpio y generoso nacimiento, a quien Dios guie en su servicio, Hernando de Figueroa, atenta la benevolencia y singular gratitud suya, para que por virtud del que ha de entrar a su alta corte de Granada, que Dios altísimo conserve, como rescatador que es el muy poderoso y afamado rey, señor de amplios y extendidos reinos y otrora y aventajada era y cumplida felicidad, el rey y señor de Castilla, para rescatar y liberar los cristianos que están debajo del yugo y servidumbre de los moros en los lugares de su reino, así como por la misma orden que lo ha acostumbrado hacer en los próximos pasados años, con la seguridad, honra y confianza que es razón y merece la calidad de su persona. Lo cual por la presente se le concede. Que es dada y escripta en la fortaleza de su real corte de Alambra de Granada, que Dios altísimo ampare, en seis días en luna de Raeg de ochocientos ochenta y nueve. Esto es verdad', en RojAS GABRIEL, Manuel, Consideraciones sobre la vida en la frontera de Jerez durante el siglo XV, en Actas de II Jornadas de Historia de Jerez. El Jerez Medieval (Jerez de la Frontera, 1989), p. 34.

${ }^{167}$ Lopez DE COCA CASTANAAR, José Enrique, Institutions on the Castilian-Granadian Frontiers 1369-1482, en BARTLETT, Robert y otros, Medieval Frontiers Societies (Oxford, Clarendon Press, 1989), p. 137.

${ }^{168}$ Torres FonTes, Juan, Instituciones, cit. (n. 1), p. 68.

${ }^{169}$ Ladero Quesada, Miguel Ángel, La frontera, cit. (n. 6), p. 57.

${ }^{170}$ Matta Carriazo y Arroquía, Juan de, En la frontera, cit. (n. 2), p. 255. 
nombramiento y establecimiento de un Alfaqueque Mayor ${ }^{171}$. Este sería elegido directamente por la autoridad y sabemos controlará a los alfaqueques menores (conocemos los de Vera, los Vélez y las Cuevas, por parte granadina; y los de Murcia, Lorca y Orihuela, por el lado cristiano) que se encontraban en los distintos sectores fronterizos.

A partir del año 1410, Diego Fernández de Córdoba se titula Alfaqueque Mayor en las negociaciones y acuerdos de tregua concertada ese mismo año con $\mathrm{Sa}^{\mathrm{c}} \mathrm{d}$ al-Amin tras la campaña de Antequera. El señor de Aguilar fue sucedido en el cargo por Jerónimo López de Saldaña, hombre de confianza de Juan II, tesorero del rey y veinticuatro de Sevilla ${ }^{172}$. Poco después de su muerte, acaecida a fines de 1438, en julio de 1439, Juan II hizo merced de por vida del oficio de Alfaqueque Mayor a Juan de Saavedra, alcalde de Castellar de la Frontera. A partir de entonces, la Alfaquequería Mayor de Castilla, sus derechos y prerrogativas se identificarán para siempre con sus descendientes directos ${ }^{173}$, siendo estos, en definitiva, los únicos que pudieron organizar rescates en la frontera desde Tarifa hasta Lorca ${ }^{174}$ hasta la definitiva anulación del oficio real por Felipe III a comienzos del siglo XVII ${ }^{175}$. Además, ya finalizada la guerra y con la desaparición de la frontera terrestre, los nuevos municipios cuestionaron los derechos de una institución que no tenía jurisdicción reconocida sobre la frontera marítima ${ }^{176}$.

\section{CONCLUSIONES}

Nuestras conclusiones se dejan resumir así:

a) Las relaciones entre Granada y Castilla no estuvieron constantemente marcadas por el signo de la violencia. Es verdad que se pueden identificar períodos más complejos en cuanto al desarrollo de la denominada "violencia fronteriza",

${ }^{171}$ García Fernández, Manuel, La Alfaquequería Mayor de Castilla en Andalucía a fines del Edad Media. Los Alfaqueques Reales, en Estudios sobre Málaga y el Reino de Granada en el V Centenario de la Conquista (Málaga, Servicio de Publicaciones, Diputación de Málaga, 1987), pp. 37-54. Cfr. con lo que establece López DE COCA CASTAÑar, José Enrique, Institutions, cit. (n. 167), p. 140, en relación al interés que despierta esta institución en la monarquía desde el siglo XIV: "All these sexplain the royal interest in controlling their activities by oficial known as the alfaqueque mayor de tierra de moros- that is, sort of superior whose jurisdition covered all the frontier. This office was first mentioned in the Cortes of Toro of 1371, but the Crown apparently did not name any person to hold".

${ }^{172}$ Rojas Gabriel, Manuel, La frontera entre, cit. (n. 30), p. 234.

${ }^{173}$ En el tumbo de los Reyes Católicos, encontramos una carta de facultad de ofiçio de alhaquequería mayor, fechada en Vitoria, 11 de junio de 1476, en la que se establece: "[...]por la presente vos damos liçencia e facultad para que al tiempo de vuestro licenciamiento por vuestro testamento e postrimera voluntad o cada quando quisierdes e por bien touierdes podades rreununciar e traspasar e rrenunciedes e traspasades en cualquier de vuestros fijos o yernos que vos quisierades los dichos vuestros oficios de alhaqueuqería mayor [...]", en T.R.C., I, 156, p. 307.

${ }^{174}$ López de Coca Castañar, José Enrique, Institutions, cit. (n. 167), p. 140

${ }^{175}$ García Fernández, Manuel, La Alfaquequería, cit. (n. 171), p. 39.

${ }^{176}$ LÓPEZ de Coca CASTAÑAR, José Enrique, Esclavos, alfaqueques y mercaderes en la frontera del Mar de Alborán (1490-1516), en Hispania, 38 (Madrid, 1978) 139, p. 289. 
pero no podríamos catalogar el conflicto campal, como el signo que definió las vinculaciones en este espacio.

b) Para regular unas relaciones que de suyo y naturalmente se van constituyendo, se hizo necesario el establecimiento de una institución que permitiera restablecer los libres flujos y vinculaciones en el espacio fronterizo. Estas son las treguas, las cuales nunca fueron comprendidas como suspensión de conflicto, sino más bien como "sobreseimiento" de las hostilidades.

c) Las treguas se manifestaron como una fórmula efectiva, sobre todo durante el siglo XV, en la materialización de unas aspiraciones de paz buscada por ambos bandos. Es interesante constatar que en los períodos de violencia fronteriza más desatada, las treguas son más constantes, lo anterior, en parte, producto de la ruptura de las mismas. Sin embargo, el hecho de su restablecimiento no hace más que demostrar el interés de ambos sectores por establecer unas condiciones pacíficas.

d) Por otra parte, las treguas serán un elemento importante en el desarrollo mismo del sultanato de Granada. Es imposible pensar en la extensión temporal del mismo, sin otorgarle la real importancia a las paces establecidas entre castellanos y granadinos, pues, estos últimos, supieron a lo largo de su historia, de la inestabilidad interna constante producto del germen siempre presente de la guerra civil. Las treguas otorgaron, en muchos momentos, un alivio a esta situación distendiéndola en el tiempo y otorgándole un respiro. Mismo caso en Castilla, la que enfrentada a las luchas sucesorias, recurrió a las treguas para aplazar los conflictos externos, centrándose en el flanco interno.

e) Por último, no podemos dejar de considerar la importancia capital de las treguas en el establecimiento de unas vinculaciones fronterizas importantes y en la regulación de una vida que ha encontrado un equilibrio en ese espacio. Es por lo anterior que se hacen cargo de las vinculaciones comerciales, pero a la vez sociales, estableciendo la actuación de instituciones que velaran por la estabilidad en ese espacio, distinto y no siempre ligado a los vaivenes del centro. Ese espacio en donde en muchos momentos, cristianos y musulmanes dialogaron, se entendieron y vivieron en paz.

\section{BiBLIOGRAFÍA}

ABELLÁN PÉreZ, Juan, Jerez, las treguas de 1450 y la guerra civil granadina, en LÓPEZ DE COCA CASTAÑER, José Enrique (editor), Estudios sobre Málaga y el Reino de Granada en el $V$ Centenario de la Conquista (Málaga, 1987).

Abellán Pérez, Juan, Relaciones Castellano-Nazaries. Jerez en los inicios del Reinado de Enrique IV (1454-1457) (Cádiz, 1985).

AMADOR DE LOS Ríos, José, Memoria histórico-crítica sobre las treguas celebradas en 1439 entre los reyes de Castilla y de Granada leida en varias sesiones de la Real Academia de la Historia (Madrid, Academia de la Historia, 1879).

Arcas Campoy, María, Cadies y Alcaldes en la Frontera Oriental Nazari (S. XV), en Al-Qantara, 20 (Madrid, 1999) 2.

Argente del Castillo Ocaña, Carmen, Cautiverio y martirio de doncellas en la fron- 
tera, en Toro Ceballos, Francisco - Rodríguez Molina, José (coordinadores), IV Estudios de Frontera (Jaén, 2002).

Argente del Castillo Ocaña, Carmen, Las relaciones de convivencia a través de los tratados de paz, en Toro Ceballos, Francisco - Rodríguez Molina, José (coordinadores), Estudios de Frontera, Convivencia, defensa y comunicación en la frontera (Jaén, Diputación de Jaén, 2002), III.

Argente del Castillo Ocaña, Carmen, Los aprovechamientos pastoriles en la frontera granadina, en CABRERA MuÑoz, Emilio (coordinador), Andalucía entre oriente y occidente (1236-1492): Actas del V Coloquio Internacional de Historia Medieval de Andalucía (Córdoba, Diputación de Córdoba, 1988).

Argente del Castillo Ocaña, Carmen, Los cautivos en la frontera entre Jaén y Granada, en Segura Graíño, Cristina (coordinador), Relaciones exteriores del Reino de Granada: IV del Coloquio de Historia Medieval Andaluza (Almería, Instituto de Estudios Almerienses, 1988).

Arribas Palau, Mariano, Las treguas entre Castilla y Granada firmadas por Fernando I de Aragón (Tetuán, Centro de Estudios Marroquíes, Editora Marroquí , 1956).

Cabrera, Emilio, Cautivos cristianos en el reino de Granada durante la segunda mitad del siglo XV, en Segura Graíño, Cristina (coordinador), Relaciones exteriores del Reino de Granada: IV del Coloquio de Historia Medieval Andaluza (Almería, Instituto de Estudios Almerienses, 1988).

Carriazo y Arroquia, Juan de Mata, Colección Diplomática de Quesada (Jaén, Instituto de Estudios Giennenses, 1975).

Carriazo y Arroquia, Juan de Mata, En la frontera de Granada (Granada, Universidad de Granada, 2002).

Carriazo y Arroquia, Juan de Mata, Un alcalde entre los cristianos y los moros, en la frontera de. Granada, en Al-Andalus, 13 (Madrid, 1948) 1.

Corriente, Federico, Diccionario de arabismos y voces afines en Iberorromance (Madrid, Gredos, 1999).

De la Granja, Fernando, Un arabismo inédito: almayarlalmayal, en Al-Andalus, 38 (1973).

De Manuel y Rodríguez, Miguel, Memorias para la vida del Santo Rey Don Fernando III (Imprenta de la viuda de don J. Ibarra, 1800).

DíAz Borrás, Andrés, El miedo al Mediterráneo: la caridad popular valenciana y la redención de cautivos bajo poder musulmán, 1323-1539 (Barcelona, Consejo Superior de Investigaciones Científicas, Institución Milá y Fontanals, 2001).

FERNÁNDEZ ARribAs, Elena, Un aspecto de las relaciones comerciales entre Castilla y Granada: El diezmo y medio de lo morisco en la segunda mitad del siglo XV, en Historia, Instituciones y Documentos, 13 (Sevilla, 1986).

Ferrer i Mallol, María Teresa, Els redemptors de captius: mostolafs, eixees o alfaquecs (segles XII-XIII), en Medievalia, 9 (Barcelona, Instituto Universitario de Estudios Medievales, Universitat Autónoma de Barcelona, 1990).

García Antón, José, Cautivos y rescates en la frontera entre Lorca y Vera en los últimos tiempos nazaries, en Homenaje al Profesor Juan Torres Fontes (Murcia, 1987), I.

García Fernández, Manuel, La Alfaquequería Mayor de Castilla en Andalucía a fines del Edad Media. Los Alfaqueques Reales, en Estudios sobre Málaga y el Reino de Granada en el V Centenario de la Conquista (Málaga, Servicio de Publicaciones, Diputación de Málaga, 1987).

García Fernández, Manuel, La alteridad en la frontera de Granada (siglos XIII al 
XV), en García Fernández, Manuel, Andalucía y Granada en tiempos de los Reyes Católicos (Sevilla. Edit. Universidad de Sevilla, 2006).

García Fernández, Manuel, Las treguas entre Castilla y Granada en tiempos de Alfonso XI, 1312-1350, en Ifigea: Revista de la Sección de Geografia e Historia, 5-6 (Córdoba, 1988-1989).

GARCíA FERnÁNDEZ, Manuel, Sobre la alteridad en la frontera de Granada (una aproximación al análisis de la guerra y la paz, siglos XIII-XV), en Revista da Faculta de de Letras. Historia, 6 (Porto, 2005).

GARCía FiTz, Francisco, ¿De Exterminandis Sarracenis? El Trato dado al enemigo musulmán en el Reino de Castilla-León durante la plena Edad Media, en Fierro, María Isabel - GarCía FITZ, Francisco, El cuerpo derrotado: Cómo trataban musulmanes y cristianos a los enemigos vencidos (Península Ibérica, ss. VIII-XIII) (Madrid, Consejo Superior de Investigaciones Científicas, 2008).

García Fitz, Francisco, Una España musulmana, sometida y tributaria, en Historia, Instituciones, Documentos, 31 (Sevilla, 2004).

GiméNEz Soler, Andrés, La Corona de Aragón y Granada, historia de las relaciones entre ambos reinos (Barcelona, Imprenta de la Casa Provincial de Caridad, 1908).

GonzÁlez Arévalo, Raúl, El cautiverio en Málaga a fines de la Edad Media (Málaga. Diputación de Málaga, 2006).

GonZÁlez JimÉnEZ, Manuel, La frontera entre Andalucía y Granada: realidades bélicas, en Ladero Quesada, Miguel Ángel (editor), La incorporación de Granada a la Corona de Castilla, Actas del Symposium conmemorativo del Quinto Centenario (Granada, Diputación Provincial de Granada, 1993).

GonZÁlez JiméneZ, Manuel, Morón de la frontera a comienzos del siglo XV, en Anuario de Estudios Medievales, 17 (Barcelona, 1987).

GonzÁlez Jiménez, Manuel, Morón, una villa de frontera (1402-1427), en Segura Graíño, Cristina (coordinador), Relaciones exteriores del Reino de Granada: IV del Coloquio de Historia Medieval Andaluza (Almería, Instituto de Estudios Almerienses, 1988).

JimÉNEZ AlCÁZAR, Jesús Manuel, Relaciones interterritoriales en el sureste de la Península Ibérica durante la Baja Edad Media: Cartas, Mensajeros y Ciudades en la Frontera de Granada, en Anuario de Estudios Medievales, 40 (Barcelona, 2010) 2.

JuAn Lovera, Carmen (editora), Colección diplomática medieval del Alcalá la Real (edición preparada por F. Toro Ceballos (Alcalá la Real, Jaén, Imprenta Esclavitud del Señor de la Humildad y María Santísima de los Dolores, 1988).

LADERO QuesadA, Miguel Ángel, Almojarifazgo sevillano y comercio exterior de Andalucía en el siglo XV, en Anuario de Historia Económica y social, 2 (Madrid, 1969).

Ladero Quesada, Miguel Ángel, La frontera de Granada, 1265-1481, en Revista de Historia Militar, 1 (Madrid, 2002).

López de Coca CaStañer, José Enrique, La Frontera de Granada (Siglos XIII-XV): El comercio con los Infieles, Cristianos y Musulmanes en la Peninsula Ibérica: La guerra, la frontera y la convivencia (León, Fundación Sánchez Albornos, 2009).

LÓPEZ DE COCA CASTAÑAR, José Enrique, Esclavos, alfaqueques y mercaderes en la frontera del Mar de Alborán (1490-1516), en Hispania, 38 (Madrid, 1978) 139.

Lopez de Coca Castañar, José Enrique, Institutions on the Castilian-Granadian Frontiers 1369-1482, en BARTLETT, Robert y otros, Medieval Frontiers Societies (Oxford, Clarendon Press, 1989).

López de Coca Castañer, José Enrique, Comercio exterior del reino de Granada, en 
Actas del II Coloquio de Historia Medieval Andaluza (Sevilla, Diputación Provincial de Sevilla, 1982), p. 375. Cfr. Peláez Rovira, Antonio, Dinamismo social en el Reino Nazari (1454-1501): De la Granada islámica a la Granada mudéjar (Granada, Editorial Universidad de Granada, 2006).

López de Coca y Castañer, José Enrique, El reino nazari de Granada y los medievalistas españoles: Un balance provisional, en La historia medieval en España: un balance historiográfico (1968-1998): XXV Semana de Estudios Medievales (Estella, 1998-1999).

Maíllo Salgado, Felipe: Acerca del significado y referente del término "exea". Contribución al estudio del medievo español y al de su léxico, en Borrego NieTo, Julio y otros (editores), Philologica. Homenaje a D. Antonio Llorente (Salamanca, Univ. de Salamanca, 1989).

Melo Carrasco, Diego, Características y proyección de las treguas entre Castilla y Granada durante los siglos XIII, XIV y XV, en Revista de Estudios Histórico-Jurídicos, XXX (Valparaíso, 2008).

Menéndez Pidal, Ramón (editor), Primera Crónica General de España (Madrid, Gredos, 1977).

Menjot, Denis, La contrabande dans la marche frontiéré murcienne au Moyen Age, en Homenaje al profesor Juan Torres Fontes (Murcia, 1987), II.

Olmo López, Antonio, El territorio: geografía y poblamiento del Jaén islámico en época nazarí, en Vidal CaStro, Francisco (editor y coordinador), Jaén en época de los nazaries (al-Andalus, S. XIII-XV), Estudios de Historia y Patrimonio Islámico y Cristiano (Alcalá la Real, Zumaque, 2010).

Perea Carpio, Carmen, La frontera concejo de Jaén-Reino de Granada en 1476, en Cuadernos de Estudios Medievales, 10-11 (Granada, 1983).

Pérez Castañeda, María Dolores, Las treguas y las suspensiones de hostilidades en la dinámica, en Toro Ceballos, Francisco - Rodríguez Molina, José (coordinadores), Estudios de frontera: Alcalá la Real y el Arcipreste de Hita. Congreso Internacional celebrado en Alcalá la Real (Alcalá la Real, 1996), II.

Pérez Gallego, Manuel, Morón y la frontera (1436-1480), en Toro Ceballos, Francisco y Rodríguez Molina, José (coordinadores), II Estudios de Frontera, actividad y vida en la frontera. Congreso celebrado en Alcalá la Real del 19 al 22 de noviembre de 1997 (Alcalá la Real, 1998).

Porras Arboleda, Pedro Andrés, El derecho de Frontera durante la baja Edad Media. La regulación de las relaciones transfronterizas en tiempo de treguas y guerras, en Estudios dedicados a la memoria del Prof. L.M. Diez de Salazar (Bilbao, 1992), I.

Porras Arboleda, Pedro Andrés, La frontera del Reino de Granada a través del libro de actas del Cabildo de Jaén de 1476, en Al-Qantara, XIV (Madrid, 1993).

Porras ARBoleda, Pedro Andrés, La organización military social en la frontera jiennense en la Edad Media, en La sociedad medieval andaluza, grupos no privilegiados. Actas del III Coloquio de Historia Medieval Andaluza (Jaén, Diputación Provincial de Jaén, 1984).

Porras Arboleda, Pedro Andrés, La presión fiscal en el Reino de Murcia al término de la Edad Media, en Historia de la Hacienda Española (épocas antigua y medieval), Homenaje al Profesor García de Valdeavellano (Madrid, Instituto de Estudios Fiscales. Ministerio de Hacienda, 1982).

Porras Arboleda, Pedro Andrés, Las relaciones entre la ciudad de Jaén y el Reino de 
Granada. La pazy la guerra según los libros de actas de 1480 y 1488, en Al-Qantara, 9 (Madrid, 1988).

Porras Arboledas, Pedro Andrés, El comercio fronterizo entre Andalucía y el Reino de Granada a través de sus gravámenes fiscales, en Baética: Estudios de arte, geografia e historia, 7 (Málaga, 1984).

Quesada Quesada, Tomás, La Serranía de Mágina en la Baja Edad Media. Una frontera con el Reino Nazari de Granada (Granada, Universidad de Granada, 1989).

Quintanilla Raso, María Concepción, El señorio de la Casa de Aguilar, en TORReS Delgado, Cristóbal (Coordinador), Andalucía Medieval: Nuevos estudios (Córdoba, Monte de Piedad y Caja de Ahorro de Córdoba, 1979).

Rodríguez Molina, José, La vida de moros y cristianos en la frontera (Alcalá la Real, Alcalá Grupo Editorial, 2007).

Rodríguez Molina, José, Libre determinación religiosa en la frontera de Granada, en Toro Ceballos, Francisco - Rodríguez Molina, José (coordinadores), Estudios de Frontera, actividad y vida en la frontera. Congreso celebrado en Alcalá la Real del 19 al 22 de noviembre de 1997 (Alcalá la Real, 1998), II.

Rojas Gabriel, Manuel, Consideraciones sobre la vida en la frontera de Jerez durante el siglo XV, en Actas de II Jornadas de Historia de Jerez. El Jerez Medieval (Jerez de la Frontera, 1989).

Rojas Gabriel, Manuel, La frontera entre los reinos de Sevilla y Granada en el siglo XV (1390-1481): un ensayo sobre la violencia y sus manifestaciones (Cádiz, Universidad de Cádiz, 1995).

Roudil, Jean., El Fuero de Baza (La Haya, 1962).

Seco de Lucena, Luis, Documentos Arábigo-Granadinos (edición crítica del texto árabe y traducción al español con introducción, notas, glosarios e índices, Madrid, Publicaciones del Instituto de Estudios Islámicos, 1961).

SeCo de Lucena, Luis, El Juez de frontera y los fieles del rastro, en Miscelánea de Estudios Árabes y Hebraicos (Granada, 1957), VII.

SuÁrez Fernández, Luis, Juan II y la frontera de Granada (Madrid, C.S.I.C, 1954).

Toro Ceballos Francisco - Rodríguez Molina, José (coordinadores), Estudios de frontera: Alcalá la Real y el Arcipreste de Hita. Congreso Internacional celebrado en Alcalá la Real (Alcalá la Real, 1996).

Torres Fontes, Juan, Dualidad Fronteriza: Guerra y paz, en Segura Artero, Pedro (coordinador), Actas del Congreso La Frontera Oriental Nazarí como Sujeto Histórico (S. XIII-XVI) (Almería, Instituto de Estudios Almerienses, 1997).

TORRes Fontes, Juan, El alcalde entre Moros y cristianos del reino de Murcia, en Hispania. Revista Española De Historia, 78 (Madrid, 1960).

TORRES FONTES, Juan, Instituciones y sociedad en la frontera murciano-granadina (Murcia, Real Academia Alfonso X el Sabio, 2004).

Torres Fontes, Juan, Las treguas con Granada de 1462 y 1463, en Hispania, 90 (Madrid, 1963).

TORres Fontes, Juan, Los alfaqueques castellanos en la frontera de Granada, en Homenaje a Don Agustin Millares Carlo, Tomo (Caja Insular de Ahorros de la Gran Canaria, 1975), II.

TORRes Fontes, Juan, Notas sobre los fieles del rastro y alfaqueques murcianos, en Miscelánea de Estudios Árabes y Hebreos (Granada, 1961), X. 
